\title{
The Safety of Farm Children and Youth: Understanding Reactions to Proposed DOL Regulatory Changes
}

\author{
A THESIS \\ SUBMITTED TO THE FACULTY OF THE GRADUATE SCHOOL \\ OF THE UNIVERSITY OF MINNESOTA \\ BY
}

MEGAN LUANNE ROBERTS

IN PARTIAL FULFILLMENT OF THE REQUIREMENTS

FOR THE DEGREE OF MASTER OF SCIENCE

ADVISOR JENNIFER KUZMA

DECEMBER 2012 
Megan Luanne Roberts

2012 C 


\section{ACKNOWLEDGEMENTS}

There are many people who have made this thesis possible. In particular, I would like to acknowledge my advisor, Jennifer Kuzma, for her expertise, guidance, and support throughout the initiation, development, and completion of this project. Additional special acknowledgement goes to committee member, Deborah Levison, who also provided invaluable insight throughout all the stages of this project. Another thank you is extended to Mary Jo Maynes for her role on the committee.

Additionally, I would be remiss if I did not acknowledge the many agriculturalists in my life that have helped to incite and expand my expertise in agricultural science and policy. Ultimately, these agriculturalists inspired my interest in the topic of children's agricultural safety. Specific thanks is directed to Gary and Lu Anne Reeck. The Reecks' skill as dairy farmers is only shadowed by their success and unwavering dedication as parents. Finally, a huge thank you is directed to another farmer, Daniel Roberts, for his unconditional support and valuable consultation throughout my thesis project—and throughout my entire master's degree experience. 


\section{ABSTRACT}

In September 2011, the U.S. Department of Labor (DOL) published its intention to revise child labor regulations for agriculture (RIN: 1235-AA06). The DOL invited public participation through submission of written comments to the Federal Register. Over 10,000 comments were received. Commenting on rulemaking is a key form of public participation, giving interested and affected parties a window of opportunity for voice in the regulation process.

This paper is a content analysis of the comments received by the DOL. NVivo software was used to code and classify a random sample of 1000 comments, distinguishing (1) stakeholder groups; (2) key concerns/themes addressed; and (3) degree of support for the proposed changes. The results of the analysis showed a lack of support for the proposal, which corresponds with the DOL's decision to withdraw the proposal in April 2012. A bottom-up participatory approach is a suggested next step to increase buyin for future children's agricultural safety policy. 


\section{TABLE OF CONTENTS}

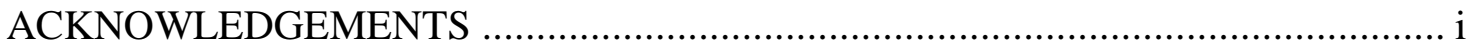

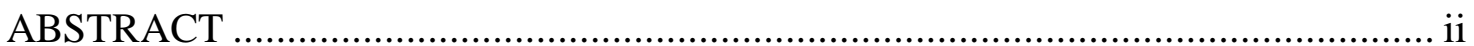

TABLE OF CONTENTS ................................................................................ ii

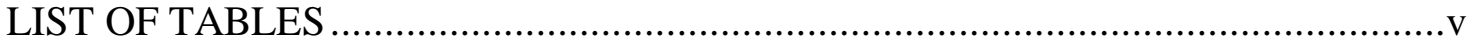

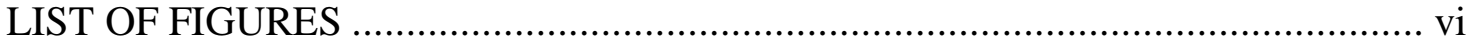

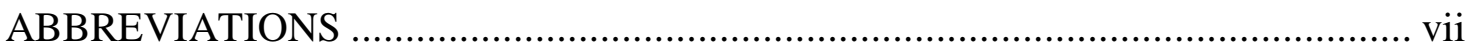

CHAPTER 1: INTRODUCTION AND BACKGROUND INFORMATION .............1

The Federal Agency Rulemaking Process ....................................................... 3

Comments: Opportunity for Public Participation in Rulemaking ..........................9

Children's Agricultural Safety at the Federal Level: A Brief History .....................15

The Current Regulation vs. the Proposed Regulation .........................................24

Public Participation Opportunities in this Proposed Rule ...................................33

CHAPTER 2: METHODOLOGY .....................................................................................38

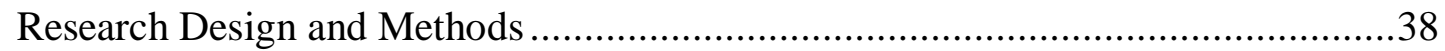

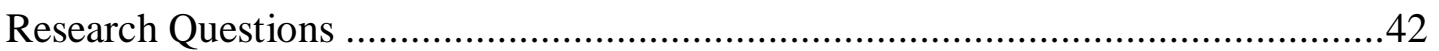

Limitations ....................................................................................... 48

CHAPTER 3: RESULTS-Who are the Stakeholders and What Did They Say? ......50

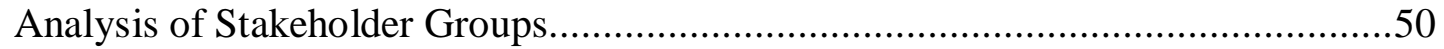


Degree of Support

Identification Top Concerns and Themes .......................................................56

Link Between Support and Stakeholder Group/Theme ...................................... 76

CHAPTER 4: DISCUSSION OF RESULTS ...................................................79

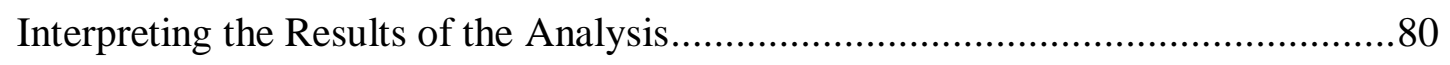

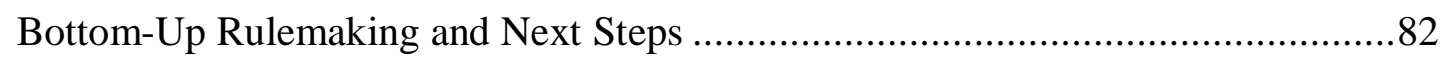

References ..............................................................................................................8

Appendix A: Parental Exemption Excerpt from DOL Proposal .................................94

Appendix B: Student Learner Excerpt for DOL Proposal ......................................99

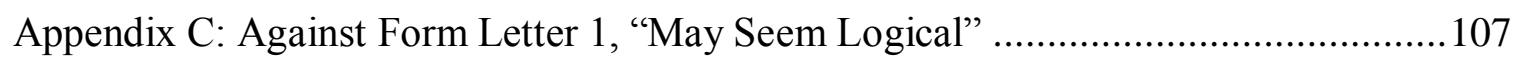

Appendix D: Against Form Letter 2, “Colorado Farm Bureau Member" ...................... 108

Appendix E: Against Form Letter 3, "Blanket Prohibition”................................... 109

Appendix F: Against Form Letter 4, “Confusing, Duplicative, and Unnecessary” ........110

Appendix G: Against Form Letter 5, “Agricultural Educator”...................................111

Appendix H: Against Form Letter 6, “Let Me Be Clear”. ....................................... 118

Appendix I: Against Form Letter 7, "Unintended Consequences" ............................119

Appendix J: Pro Form Letter 1, "Changes are Long Overdue” ................................. 120 


\section{LIST OF TABLES}

Table 1: Federal Children's Agricultural Safety Agenda ..........................................21

Table 2: Work and Non-Work Injuries of Youth on U.S. Farms, 2009 ........................24

Table 3: An Overview of the Current Regulation versus the Proposed Regulation .........25

Table 4: Stakeholder Groups (Mutually Exclusive Codes) ........................................43

Table 5: Degree of Support (Mutually Exclusive Codes).......................................44

Table 6: Themes Codes and Descriptions ..........................................................45

Table 7: Stakeholder Group Example Quotes........................................................51

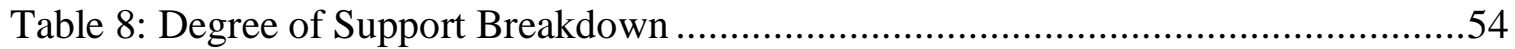

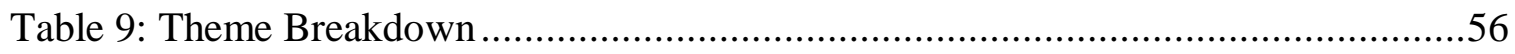

Table 10: Stakeholder Groups and Degree of Support ............................................77 


\section{LIST OF FIGURES}

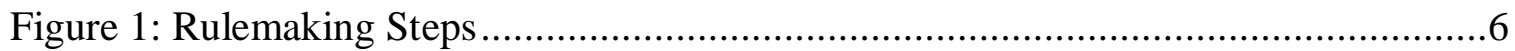

Figure 2: Example of "Against" Comment with Focus on Anecdotal Evidence ..............82 


\author{
ABBREVIATIONS \\ APA $=$ Administrative Procedure Act \\ DOL $=$ Department of Labor \\ $\mathrm{CDC}=$ Centers for Disease Control \\ $\mathrm{EO}=$ Executive Order \\ FSLA = Fair Standards Labor Act \\ HHS $=$ Health and Human Services \\ $\mathrm{HO}=$ Hazardous Occupation Orders \\ NAGCAT $=$ North American Guidelines for Children's Agricultural Tasks \\ $\mathrm{NIOSH}=$ National Institute for Occupational Health and Safety \\ NPRM $=$ Notice of Proposed Rulemaking \\ OFR = Office of the Federal Register \\ OIRA $=$ Office of Information and Regulatory Affairs \\ $\mathrm{OMB}=$ Office of Management and Budget \\ USDA = United States Department of Agriculture
}




\section{CHAPTER 1: INTRODUCTION AND BACKGROUND INFORMATION}

On September 2, 2011, the U.S. Department of Labor (DOL) announced in the Federal Register its proposal "to revise the child labor regulations issued pursuant to the Fair Labor Standards Act, 29 U.S.C. 212, which sets forth the criteria for the employment of minors in agriculture" (29 CFR 570). The proposal suggested changes to the FLSA "Child Labor Regulations, Orders and Statements of Interpretation: Violations-Civil Money Penalties" (RIN: 1235-AA06). These changes would alter the criteria set forth for permissible employment of minors in agricultural and nonagricultural settings. The Notice of Proposed Rulemaking (NPRM) focused on E-1 of the regulation and the current agricultural hazardous occupations orders (HO). The NPRM cites relatively high levels of youth fatalities and injuries in the agricultural sector as an instigator for the DOL's proposal (76 FR 171, 54843). In regards to the proposed revision to the FLSA, interested parties were initially asked to submit written comments by November 1, 2011, but due to requests by multiple national agricultural business organizations the comment period was extended by 30 days (76 FR 210, 67105). The comments received regarding the proposed FLSA rule changes totaled 10,325 and are publically available through the website Regulations.gov (http://www.regulations.gov/\#!docketBrowser;rpp=25;po=0; D=WHD-2011-0001; dct=PS).

On February 1, 2012 the Department of Labor's Wage and Hour Division announced that due to comments received in Fall 2011, it would re-propose the portion of the rule regarding the "parental exemption" for child labor in agriculture to better reflect 
"rural traditions" and would request additional comments in early summer (Alexander, 2012). However, on April 26, 2012, the DOL announced that it would withdraw its attempt to revise child labor regulations for agriculture and would focus on educational outreach instead (Lamont, 2012). The political pressure leading to this outcome does not necessarily indicate a lack of federal interest in child safety, but rather a strong desire to maintain the rural tradition of children working on farms.

The proposed revision to child labor regulations represents an issue with direct significance to the health and safety of agricultural workers and their families in the United States. There are 56,000 hired farmworkers under the age of 16 in the US (29 CFR 570). Farm parents value and sometimes need their children's assistance in a variety of farm-related tasks. Equally valued is the learning that farm kids do "on the job" including practical direct knowledge in growing crops, animal husbandry, and machinery repair, among other things, as well as indirect knowledge in responsibility, perseverance, and more. Also, a high percentage of current farmers were once farm kids.

Still, too many youth are injured or die due to their work (and play) on farms. Every year in the United States over 100 children and youth are killed on farms (CDC, 2012). Furthermore many more are injured on farms, although reports differ greatly on the exact number, potentially due to discrepancies of what constitutes an "injury." The CDC and the United States Department of Agriculture (USDA) estimated about 15,00016,000 injures in 2009 (CDC, 2012) (USDA, 2012). Another estimate lists youth injuries per year in agriculture at 100,000 (Levine, 2003). What age is the appropriate age for which farm tasks? Should farm children be kept away from all farm tasks? What about 
neighbor children? Children of agricultural migrant workers are yet another category, as they may work alongside their parents. Farm families (both adults and children) have strong opinions about the proposed regulatory changes, but so do health and safety experts.

In this chapter, a brief overview of the federal agency rulemaking process is discussed with special attention given to the opportunities for public participation within the process. Next, children's agricultural safety regulation is summarized though a historical context. Then, a closer examination is given to the proposed rule in question and compared and contrasted with the current regulation. Finally, an overview is given on the amount of public participation that occurred in response to the DOL's NPRM for "Child Labor Regulations, Orders and Statements of Interpretation: Violations-Civil Money Penalties" (RIN: 1235-AA06).

\section{The Federal Agency Rulemaking Process}

The federal agency rulemaking process refers to the governmental standards set to guide the development, revisal, and implementation of regulations. Final rules enacted by federal agency, board or commission hold the same legal bearing as congressional legislation, judicial judgment, or presidential order (OIRA, 2012). Rulemaking occurs outside the legislative process, but the authority to enact rules typically comes from Congress. When Congress passes a law to create an agency, it will, in most cases, also grant that agency the authority to develop regulations to govern related activities. Furthermore, Congress can direct existing agencies to develop regulations to address a specific public problem, for example through a Congressional law of statute. 
Rulemaking may come about due to a variety of catalysts. These include (but are not limited to) new technologies, new research findings, public demand, presidential directives, congressional recommendations, related lawsuits, Office of Budget and Management "prompt letters," intra- or interagency motivation, and/or concern over societal problems, such as a high level of accidents affecting a certain activity (OFR, 2011). In the case of the proposed changes regarding the FLSA and children's agricultural safety, the DOL emphasized the high level of associated fatal and non-fatal accidents as a major factor contributing to their initial September 2011 proposal (FR 76 No 171).

Agencies cannot pass rules that are not within their statutory authority or within the realm of constitutionality. All activities of the rulemaking process must be done in accordance with the Administrative Procedure Act (APA). The APA, enacted in 1946, provides federal agencies with the power to enact rules and also sets forth the official process to govern their authority (Lubbers, 2006). The APA also includes the procedure for including public participation in rulemaking. Public participation through stakeholder involvement may occur at a number of different steps. A common avenue for public participation in the rulemaking process includes written submission of comments and/or oral testimony; this participation is known as the "open public process" (OFR, 2011). For the general public, submitting comment to the Federal Register is the most common form of participation. In addition to the APA, a series of regulatory reforms passed in the late 1970s also guides the federal rulemaking process (Lubbers, 2006). 
Agencies publish a regulatory agenda biannually and a regulatory plan annually (known collectively as the Unified Agenda). The Unified Agenda allows the public to be aware of upcoming proposed rules. In addition, agencies must individually announce in the Federal Register proposals to change specific rules. The document that announces the proposed rule is known formally as the Notice of Proposed Rulemaking (NPRM) and is required by the APA. The intent of the NPRM is to adequately inform the public of upcoming rulemaking and allow time for public comment and participation (OFR, 2012).

The two different types of rulemaking, formal and informal, affect the ways in which the public can participate. In the less common formal rulemaking, federal statues require a formal public hearing to be held to gain public comment. The exceptions which trigger formal rulemaking are outlined in section 554 of the APA (ABA, 2001). A formal public hearing allows participation through submission of oral or documentary evidence, cross-examination of witness, and rebuttal of evidence. An agency may ask that parties interested in participation in the hearing prove that their contributions serve a threshold level of purpose (ABA, 2001).

The more common informal rulemaking, established by section 553 of the APA, accounts for the vast majority of federal regulation (see Figure 1 for an overview of the steps in informal rulemaking). In informal rulemaking, also known as notice-andcomment rulemaking, the public may participate by submitting written comments to the Federal Register following a public notice and request for comments by the corresponding agency. No public hearing is required in informal rulemaking, although an agency may choose to both invite written comments and hold an oral hearing. 
Figure 1: Informal Rulemaking Steps
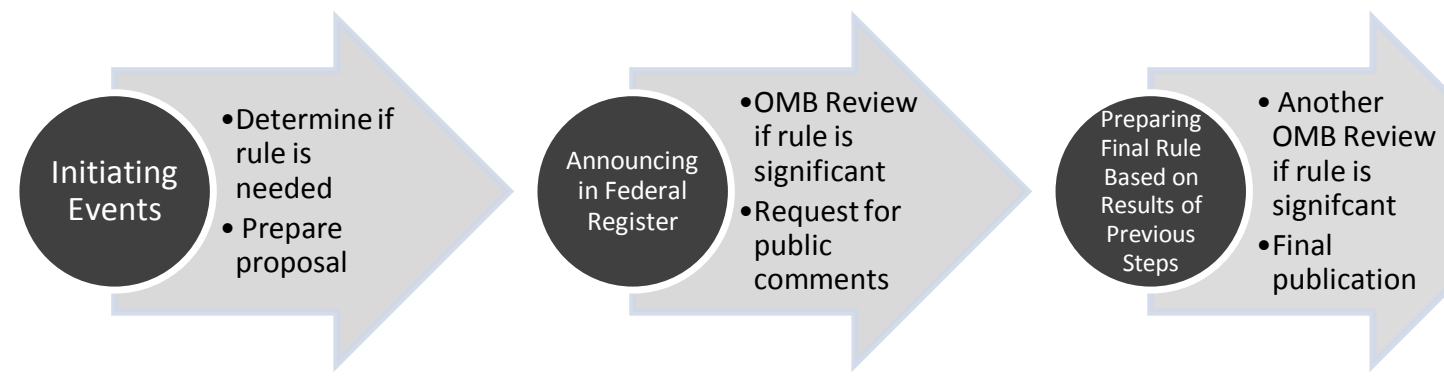

Figure adapted from: ICF Consulting (2003) “The Reg Map: Informal Rulemaking,” Reginfo.gov. http://www.reginfo.gov/public/reginfo/Regmap/index.jsp.

Following the initial comment period, the rule may be revised, the comment period may be extended, notification may be made for another comment period, or a combination of these three options may be undertaken. Publication of the final rule at least 30 days prior to its effective date is the final step in notice-and-comment rulemaking; publication of the final rule must include summary, effective date, and supplementary information in accordance with the APA (Lubbers, 2006). The supplementary information of the final rule includes a basis and purpose statement that "sets out the goals or problems the rule addresses, describes the facts and data the agency relied on, responds to major criticisms in the proposed rule comments, and explains why the agency did not chose other alternatives" (OFR, 2011). A response to the major criticisms and an explanation of the agency's decision process must be included in the final rule; therefore, it is imperative that before drafting the final rule an agency responds to significant concerns raised in submitted comments received. The agency does not need to respond to all comments raised, but must address overarching substantive concerns 
raised, such as viable alternatives, respected experts' opinions, additional new scientific data, persuasive new policy arguments, strong and convincing criticism, and any other significant relevant concerns (OFR, 2011). Finally, the Office of Budget and Management must review all proposed rules before the publication of the proposal in the Federal Register and before publication of the final rule in the Federal Register if the rule is deemed "significant" (ICF, 2003).

In addition to the normal steps of informal and formal rulemaking, due process is dictated in rulemaking by analyzing the impact of the following three considerations "(1) the strength of the private interest, (2) the risk of error and the probable value of additional or substitute procedural safeguards to avoid error, and (3) the strength of the Government's interest" (ABA, 2001). According to the American Bar Association, adequate notice by an agency to the public of the opportunity to submit comments and/or give oral testimony is typically sufficient due process for most agency rulemaking (ABA, 2001). If any of the three considerations listed above or a combination thereof is deemed substantially high, additional due process is warranted in the rulemaking process. The APA and the constitutional rights of individuals in the United States ultimately dictate the use of due process in rulemaking.

While the APA is the central piece of legislation governing all federal rulemaking, there are a number of other important judicial, executive, and legislative documents that impact the rulemaking process. First, the Federal Register Act of 1935 establishes the Federal Register as the official publication medium for proposed and final rules (44 U.S.C. Chap. 15). The Federal Advisory Committee Act of 1972 helps guide the 
formation, operation, and disintegration of advisory committees and their role in rulemaking (5 U.S.C. Appendix 2). The Paperwork Reduction Act of 1980 established the Office of Information and Regulatory Affairs (OIRA) within the Office of Management and Budget (OMB) (44 U.S.C. 3501 et seq). OIRA reviews government collections of information and under EO 12866, OIRA examines drafts of proposed and final rules and conducts cost/benefit analysis. The Regulatory Flexibility Act, also passed in 1980, directs agencies to pass regulations the fit the scale and abilities of the affected parties (5 U.S.C. 601 et seq). The Regulatory Flexibility Act aims to be cognizant of possible burdens to small businesses, small non-profits, and small governmental organizations/jurisdictions by regulations. The Negotiated Rulemaking Act of 1990 (reauthorized in 1996) encourages agencies to utilize a public negotiation process during the rulemaking when negotiation is projected to result in a more meaningful outcome (5 U.S.C. 561 et seq). Finally, the Congressional Review Act of 1996 give Congress the authority to review final rules; agencies must submit a copy of any "major" final rule, a concise summary, and a proposed effective date to both houses of Congress before the proposed effective date (U.S.C. 5 Chapter 8). Congress may disapprove rules, resulting in the rule having no further force.

In addition to the impact Congress has on rulemaking, rulemaking has been impacted significantly by visions of various presidential administrations. Executive orders by recent administrations - Clinton, Bush, and Obama—have all had notable impacts on regulatory process. The Obama Administration has issued two major executive orders, EO 13497 and EO 13563, concerning the regulatory planning and 
review process (OIRA, 2012). EO 13497 removed changes to the regulatory process implemented during the Bush Administration and restored regulatory planning and review to the longstanding format implemented under the Clinton Administration's EO 12866. EO 13563, the second important EO regarding rulemaking issued by the Obama Administration, directs agencies to issue rules that protect "public health, safety and our environment while promoting economic growth, innovation, competitiveness, and job creation" (Obama, 2011). The President directed both quantitative and qualitative costs and benefits to be analyzed during rulemaking with special attention paid to fairness, transparency, improving equity, reducing public burden, decreasing redundancy, and increasing cost effectiveness. Furthermore, this EO places increased emphasis on meaningful public participation during the regulatory process, stressing the use of modern technology to enable wider citizen engagement (see Public Participation section below).

\section{Comments: Opportunity for Public Participation in Rulemaking}

The process of notice-and-comment rulemaking allows for public participation through the written and/or oral comments. According to Regulations.gov, public participation in rulemaking refers to the interaction of individuals, businesses, trade associations, non-profit organizations, academia, private researchers, and other nongovernmental actors with the informal regulatory process (2012). Gene Rowe and Lynn J. Frewer of the United Kingdom's Institute on Food Research detail public participation more broadly: "involvement may be achieved in different ways: at the lowest level, the public may be targeted with enhanced information (e.g., about risks). At higher levels, public views may be actively solicited through such mechanisms as 
consultation exercises, focus groups, and questionnaires. At still higher levels, members of the public may be selected to take part in exercises that provide them with a degree of decision-making authority" (2000).

The most basic form of public participation in the rulemaking process is a written comment. A written comment consists of a publicly submitted response to a proposed regulation; the comment represents the submitter's opinion of the proposed rule and may be as short as a few sentences or as long as thousands of pages and include detailed supporting quantitative or qualitative data (Regulations.gov, 2012). Comments are requested during the NPRM, and the public typically has 60 days in which to submit a comment.

Since informal rulemaking is done outside the realms of the democratically elected Congressional and Executive branches, participation in the rulemaking process via written or oral comment accounts is one of the few ways the general public can interface directly with the regulatory process. Rules that are created and refined with a high level of public participation can achieve greater effectiveness, legitimacy and quality. Furthermore, high levels of transparency during the rulemaking process can also result in better outcomes. Many of the social and economic rights and equalities individuals enjoy in the United States rely in large part to federal regulation, so achieving legitimate high quality results through transparent participatory rulemaking has important social welfare implications. (Coglianese, 2009).

A highly transparent process from the first instigation of the rulemaking process can assure the rule is integrated with the goals of democracy. Transparency and 
participation are closely intertwined but are nonetheless two separate concepts.

Transparency can and should occur both before and after the request for comments for a proposed rule, even if the public is only asked to participate in a limited way via the traditional comment period (Coglianese, 2009). Good public participation in a transparent rulemaking process can inform the democratically elected congressional and executive branches of the public's will on the matter and leave a "more robust record" in the chance of judicial review of the regulation (Coglianese, 2009).

While this thesis focuses on the opportunity for public involvement through an agency's request for written comment after the proposed rule has been drafted, there are many avenues an agency may employ to garner public input in the informal rulemaking process before and after the traditional comment period. Before a rule is even in the beginning stages of formation, agencies may take steps to involve the public via informal conversations and unstructured meetings with interested individuals and organizations. If a public petition sets the rulemaking process in motion, the agency may publish the submitted petition in the Federal Register and request comment before it begins drafting a proposed rule. While all rulemaking requires a NPRM, agencies may also publish an Advance Notice of Proposed Rulemaking (ANPRM) to formally invite public participation before an upcoming proposed rule is even drafted. Lastly, as aforementioned, the Negotiated Rulemaking Act of 1990 sets forth a procedure for agencies to invite members of interested parties to meetings in an attempt to reach consensus through informal negotiation before the proposed rule is drafted. Agencies take this consensus into consideration when decisionmaking but do not need to endorse or 
include the ideas of the group consensus in the proposed or final rule. During the written comment period in informal rulemaking, an agency may also choose to hold public hearings to gain oral comments and allow the public to submit data in person (OFR, 2011).

Early in 2009, the Obama Administration set forth a goal of improving the federal rule-making process, with a focus on utilizing public participation and transparency to increase legitimacy and substantive quality (Coglianese, 2009). While the previous paragraph describes a number of methods already established for increasing public participation, the federal rulemaking process currently leaves room for improvement particularly in transparency and participation. Even the much advocated negotiated rulemaking (Harter, 2001), has very vocal critics (Coglianese, 1997). Critics suggest that negotiated rulemaking may enable one special interest group to sway the whole process or even if true group consensus is reached, the regulator may not legally have to incorporate the group's suggestions into the final rule (Calcott, 2007).

To address criticism and encourage more public participation, the non-partisan, non-governmental Presidential Transition Task Force on Transparency and Public Participation in the Federal Rulemaking Process suggested a set of 26 recommendations to improve rulemaking in the then-new Obama Administration (Coglianese, 2009). Highlights of the recommendations include enhanced use of and greater reliance on online resources, interactive comment-periods, and encouragement of a fully open-door policy during participation (Coglianese, 2009). 
Two executive orders relate directly to the Obama Administration's goal of increasing transparency and public participation: EO 13497 and EO 13563. In terms of public participation via written comments, EO 13563 contains the most important related directive in Section 2, part b, which promotes greater use of Regulations.gov as a central online forum for posting related regulatory documents and as an onestop website that gives the public a meaningful opportunity to comment online (Obama, 2011).

Additionally, it is recommended that when feasible all comment periods should be at least 60 days in length to give ample opportunity for participation. E-government has been championed since the early 1990s in the Clinton Administration, Regulations.gov was launched in 2003 under the Bush Administration, and Regulations.gov has been further emphasized in the Obama Administration (Coglienese, 2009). Regulations.gov has been re-designed/improved 15 times between 2009 and December 2012 to increase the comment submitters' experience, with a focus on overall usability, opportunity for feedback, and easy to understand text (Regulations.gov, 2012). Some agencies no longer accept comments via e-mail, fax or traditional mail and use Regulations.gov as the only means to submit written comments (Regulations.gov, 2012).

Online comment submission results in a number of benefits for public participation. Online comment management can be less costly to federal agencies. The ease of online comment submission makes participation in federal decision-making hypothetically available to more people and more diverse demographics. The website is an onestop shop for interested individuals and public organizations to access material related to the proposed rule. An online Docket Folder, posted in the same area where 
comments can be submitted, contains all relevant official and supporting materials on the proposed rule. Regulations.gov also enables online access to all of the submitted comments and creates the ability to easily group comments by submitter or topic (Lubbers, 2006). Before the advent of E-governance, the general public's ability to access a rule's docket folder was extremely limited by time, proximity to Washington DC, and feasibility.

Although some may argue that the internet age and online comment submission brought the opportunity for public participation to the masses, others find the electronic era reduced the quality of comments. A case study of the Environmental Protection Agency's 2004 mercury rulemaking showed that only a small portion of the comments received by the EPA contained new information, with a large number of comments simply derived from a form letter contained in a chain e-mail (Shulman, 2012). Stuart Shulman, who authored the research article "The Case Against Mass E-mails: Perverse Incentives and Low Quality Public Participation in U.S. Federal Rulemaking," writes his paper "raises doubts about the notion that online public participation is a harbinger of a more deliberative and democratic era" (2012). With the online system a higher quantity of comments can now be easily submitted, so agencies must be prepared to analyze and manage a greater volume of comments (Lubbers, 2006). Similarly, earlier research which focused more on the quantity of comments in general rather than the online submission of comments, found large quantities of comments cost agencies time and money, and many comments did not contribute new ideas to the deliberative agency decisionmaking process (Rossi, 1997). 
However, it is clear written comments $\underline{d o}$ matter, regardless of how they were submitted, the quantity, or the quality. Public participation through comment submission can impact federal rulemaking in meaningful ways. Critical comments received in the first round of a request may trigger a second comment period, an extension of the original comment period, significant revision of the original proposal, additional data collection, and/or a complete withdrawal of the proposal (OFR, 2011). If the rule proceeds, all major criticisms of the rule must be either reflected in the final rule or at least addressed in the supplementary information section of the final rule. Conversely, significant comments in favor of a regulation may help an agency justify the new regulation and display public support for the rulemaking.

\section{Children's Agricultural Safety at the Federal Level: A Brief History}

Before the late 1980s, agricultural safety garnered little attention at the national level. With the exception of the regulatory protections for youth provided by the Department of Labor through the Fair Labor Standards Act (FLSA) in 1938 and its subsequent updates, agricultural safety researchers agree the United States lacked a unified agricultural safety agenda until 1988. Before addressing this unified agenda, it is helpful to understand the FLSA and its impacts on youth agricultural workers.

The FLSA, enacted in 1938, (U.S.C 29 Sec 201) prohibits the jobs available to children under the age of sixteen or eighteen based on the relative hazard of the vocation. However, these prohibitions are not uniform across all groups of children. Since its beginnings, the FLSA has included exemptions for children being employed in any occupation by their parents (called the parental exemption). Additionally, the original 
1938 version of the FLSA had broad exemptions for agriculture. "Under the original Act, youth of any age could be employed in all phases of agriculture, even hazardous work, whenever the applicable state compulsory school-attendance law did not require the minor to attend school" (FR 76:171 54838). In 1949, the FLSA agricultural exemption was amended to close a loophole that had resulted in some students not attending school. The 1949 amendment was designed to increase attendance at school by modifying "the exemption from the child labor requirements with respect to the employment of children in agriculture so that it applied only to periods of time that were outside of school hours for the school district where the children lived while so employed (FR 76:171, 54838). The last major amendment came in 1966, which broadened the regulation to include agricultural employment and resulted in subsequent rulemaking by the DOL, which was finalized in 1970. The 1970 final rule is essentially unchanged today and forms the basis of current children's agricultural safety regulation (FR 76:171 54838).

Although there were regulations in place before the 1980s, agricultural safety experts noted a lack of a unified national agenda for agricultural safety. In 1988, the University of Ohio and The Ohio State University jointly held a national conference focusing on both the lack of a national research agenda in agricultural safety and the highly hazardous characteristics of agricultural work (Frank, 2004). This seminal conference resulted in a pioneering report in the field of agricultural safety. This report, Agriculture at Risk, included the recommendations from experts involved in the conference and proved instrumental to the National Institute for Occupational Safety and Health's (NIOSH) decision to focus more closely on agricultural safety. It helped NIOSH 
focus on creating a unified national agenda for research, education and outreach within the area of agricultural health and safety (Frank, 2004). In 1990, under a directive from Congress, the Centers for Disease Control and Prevention (CDC) and NIOSH developed the Agricultural Health and Safety Initiative, which established and funded agricultural safety and health centers in 20 states across the nation (CDC, 2012).

While the largest focus at that time was on reducing fatalities and injuries that caused serious disability, other issues of focus included pesticide-related morbidity, cancer incidence, respiratory health, and migrant worker healthiness. A specific and important focus also included children, with special funding devoted to an agricultural health and safety center for child and adolescent agricultural safety issues (Frank, 2004). This center is The National Children's Center for Rural and Agricultural Health and Safety (National Children's Center) located at the Marshfield Clinic in Wisconsin. The National Children's Center has been a leading organization in the area of children's agricultural safety since 1992. In the 1980s, approximately 300 youth died at work and play per year on farms (Rivara, 1985). After the establishment of the National Children's Center, but probably due to multiple factors, total annual youth farm fatalities decreased significantly by the mid-1990s to a number well below 200 deaths per year (Frank, 2004).

Still, the number of deaths and injuries by youth at work and at play on farms remained high. During the time period of 1992-1997, agriculture accounted for $40 \%$ of youth work fatalities across all industries (BLS, 1999). In 1996, Congress approved and funded the National Action Plan for Childhood Agricultural Injury Prevention, which enabled the National Children's Center to develop annual action plans with wide 
stakeholder involvement. Then, in 1999, at the urging of farm parents, the National Children's Center developed the North American Guidelines for Children's Agricultural Tasks (NAGCAT) (Gadomski, 2006). Parents, safety professionals, child development exports, adolescents, and other key stakeholders worked together to reach consensus and develop the guidelines. Placing particular emphasis on child development methodologies and job hazard analysis allowed the guidelines to assist parents "in matching a child's physical, mental and psychosocial abilities with the requirements of certain farm jobs" (Gadomski, 2006). NOISH embraced a grassroots and multidisciplinary approach in the development of NAGCAT, which represents an excellent example of in-depth public participation outside the regulatory sphere. NAGCAT targets seven to 16-year-old youth working on farms and consists of 62 guidelines in seven broad categories. The guidelines address the most common routine jobs performed by children on farms. Each of the 62 guidelines consists of a colored illustration of the task, a recommendation for adult supervision and intervention in the task, a general description of the hazards and safety precautions associated with the task, and importantly, a flowchart designed to help adults assess the child's ability to complete the task safely (Gadomski, 2006). The NAGCAT recommendations can emphasize developmental maturity and individual ability in assessing job readiness, whereas a regulation must generally rely on less fluid cut-offs such as strict age requirements.

The last decade has seen another significant drop in farm fatalities and injuries. From 1998-2009 (the year before NAGCAT was formed until the most-up-to-date year of data), the youth farm injury rate has declined from 18.8 to 9.9 injuries per 1000 farms 
(HHS, 2011). The National Agricultural Statistic Service calculates an even lower injury rate for youth at 7.2 injuries per 1,000 farms in 2009 (NASS, 2012). The average number of youth farm fatalities also declined significantly in the last decade to its current rate of about 113 deaths per year (HHS, 2011). The US Department of Health and Human Services, CDC and NOISH agree the number of injuries and fatalities continues to be a public health concern, but believe further education and implementation of NAGCAT recommendation could reduce injuries and fatalities further. HHS, CDC, and NOISH credit the reduction in injuries and deaths to the formation of the NAGCAT recommendations, as well as a number of other governmental and non-governmental factors (HHS, 2011). These factors include an increase in the level of high-quality agricultural safety research, a willingness of farmers to "bury unsafe traditions" and replace them with safer youth practices, a high level of financial and social support for non-profit organizations such as Farm Safety 4 Just Kids, community based youth safety programs, and media coverage (HHS, 2011). Furthermore, the number of youth visiting, working, or living on farms has declined, which lowers the total potential number of youth to be injured. However, in addition to the absolute total for injuries and fatalities declining, both the injury and fatality rates per 1000 workers and per 1000 farms have also declined (NASS, 2012).

Another major development in the national children's agricultural safety agenda was the National Occupational Research Agenda's (NORA) Agricultural, Forestry, and Fishing Sector (AgFF) goals published in 2008 and updated in 2012. The latest set of national occupational safety and health goals for agriculture, fishing and forestry are 
currently in the draft stage and available now for public review and comment (CDC, 2012). In the agenda, special populations at risk, such as young and old workers, migrant and seasonal workers, women, persons with disabilities, and racial and ethnic minorities, receive particular focus.

Youth migrant workers represent a particularly important and difficult group to protect with children's safety regulations, educational approaches, NORA initiatives, and NAGCAT guidelines. A recent study of a NORA AgFF project by University of California Berkley researchers found that historically "there are few points of easy access to young [migrant] farmworkers, and the specific health and safety needs of this worker population are often neglected by traditional agricultural youth development programs as well as by general health and safety training targeting adults" (Baker and Meyers, 2011). Recently, special focus has been given to addressing the unique challenges in protecting youth migrant workers. NOISH and the CDC now offer some of their youth worker fact sheets and publications in Spanish, including "Are You a Teen Worker/¿Eres un adolescente y trabajas?" (DHHS, 2012). However, this bilingual publication does not currently cover youth agricultural regulations (DHHS, 2012). To overcome this gap in children's safety interventions for migrant worker youth, researchers are currently exploring utilizing high school English as a Second Language courses to introduce both farmworker safety curriculum and language education. Researchers, who were funded under a NORA project, have indicated that their "findings have met with enthusiastic response among farmworker advocates, who have expressed interest in adopting this curriculum in schools in their regions" (Baker and Meyers, 2011). 
Table 1: Federal Children's Agricultural Safety Agenda

\begin{tabular}{|l|l|}
\hline Initiatives/Organizations/Regulations & Description \\
\hline $\begin{array}{l}\text { The Department of Labor's "Child Labor } \\
\text { Regulations, Orders and Statements of } \\
\text { Interpretation: Violations-Civil Money } \\
\text { Penalties (RIN: 1235-AA06)" }\end{array}$ & $\begin{array}{l}\text { Regulates the employment of children in the } \\
\text { agricultural sector through the FLSA. Focuses } \\
\text { on Agricultural Hazardous Occupation Orders } \\
\text { and civil money penalties for violations. Last } \\
\text { major agriculture update occurred in the 1970s. }\end{array}$ \\
\hline $\begin{array}{l}\text { The National Children's Center for Rural } \\
\text { and Agricultural Health and Safety at the } \\
\text { Marshfield Clinic }\end{array}$ & $\begin{array}{l}\text { Conducts research and outreach on children's } \\
\text { agricultural safety. Releases yearly agricultural } \\
\text { safety action plans goals developed with } \\
\text { stakeholders. Established in 1992 under the } \\
\text { auspices of a1990 directive from Congress to } \\
\text { create the Agricultural and Health Safety } \\
\text { Initiative, a joint NOISH and CDC project that } \\
\text { also established 19 other agricultural safety } \\
\text { centers. }\end{array}$ \\
\hline $\begin{array}{l}\text { Marshfield Clinic's North American } \\
\text { Guidelines for Children's Agricultural } \\
\text { Tasks (NAGCAT) }\end{array}$ & $\begin{array}{l}\text { Recommends safety protocols for 62 common } \\
\text { youth agricultural tasks. Created for direct use } \\
\text { by children. Initiated in 1999 at the urging of } \\
\text { farm parents with NOISH and CDC input. } \\
\text { Represents an excellent non-regulatory bottom- } \\
\text { up approach to children's safety. }\end{array}$ \\
\hline $\begin{array}{l}\text { National Occupational Research Agenda's } \\
\text { Sector (AgFF) Goals }\end{array}$ & $\begin{array}{l}\text { Establishes goals for occupational health and } \\
\text { safety. Has section devoted to special } \\
\text { populations, including migrant workers and } \\
\text { young people working in AgFF. Has two } \\
\text { different versions, including a 2012 draft. }\end{array}$ \\
\hline
\end{tabular}

The NOISH's NAGCAT, NORA AgFF, and Safety and Health Centers combine to form the basis of the federal agenda for both children's and overall agricultural health and safety (see Table 1); however, this agenda operates primarily outside of the regulatory sphere. As described above in the overview of the Fair Labor Standards Act (FLSA) at the beginning of this section, children's labor safety regulation dates back to the FLSA in 1938 (U.S.C 29 Sec 201) (Marienga, 2007). The final regulatory update to 
the FLSA, which forms the current children's agricultural safety regulation, went into effect in 1970 and has been essentially unchanged for agricultural employment in the subsequent 40 years (Marienga, 2007). Additionally, the generalized age threshold for hazardous jobs in agriculture is 16-years-old as opposed to the age threshold for hazardous jobs in non-agricultural employment being 18-years-old (Marienga, 2007). Furthermore, a child of any age working on his/her parent's farm or on the farm of a person standing in the place of his/her parents is exempt from federal child labor laws and all hazardous occupation orders (DOL, 2012). Due to the numerous regulatory gaps in children's agricultural labor policy, safety researches have suggested it is time for an update (Marienga, 2007). The first major proposal for to update children's agricultural safety regulations under the FLSA occurred in September 2011. The next section includes a much closer and detailed analysis of the current regulations enacted in 1970 and the proposed regulations of 2011.

Another complicated aspect of children's agricultural safety are the many different categories of youth on farms. Currently, the National Agricultural Statistic Service (NASS) collects data on youth farm injures on behalf of NOISH. A phone based comprehensive survey of 50,000 farm operators by NASS was conducted in 2001, 2004, 2006, and 2009. Using the data from a random sample of 50,000 farm operators, NASS projects the number of injuries that occurred in each year across the total population. The total population numbers in 2009 were 2,200,100 farms ${ }^{1}$ with $27,646,594$ total youth working, visiting, and/or living on those farms (NASS, 2012). Of the total youth,

\footnotetext{
${ }^{1}$ The USDA defines a farm as any place with $\$ 1000$ or more of agricultural goods were sold or normally would have been sold (O’Donoghue, 2009).
} 
1,030,000 million children resided on farms, and 748,938 were employed on farms as hired (non-household) youth or working household youth (NASS, 2012) (CDC, 2012). While the number of farms has increased slightly by two percent between 2001 and 2009, the total youth on farms and the total youth working on farms have declined during that same time period by 9.5 million youth and 400,000 youth, respectively. NASS also categorizes youth by gender, age (0-9,10-15, and 16-19), residence of the youth (lives in the farm household or lives off the farm), and place of work (works on the respective farm or does not work on the farm where injury occurred).

Furthermore, injuries are categorized as being work-related or non-work-related (see Table 2). For example, a youth could be a member of the farm household, work on the respective farm, but be injured during a non-work event, which would fall outside of both current and proposed regulation. NOISH has identified non-work farm-related injuries of children aged 0-6 to be one of the greatest areas of concern, because this falls outside of both regulations (which are geared towards working youth) and NAGCAT (which are geared towards youth over seven). While younger children are one of the categories of greatest concern to NOISH, the most injuries, 6912, occurred in youth aged 10-15 in 2009 (NASS, 2012). Of the total 2009 youth farm injuries of 15,876, about onefifth (3191) were work-related. Of the 3191 youth who injured themselves in a workrelated event, 70 percent were male. According to this data, in 2009 there were about 1.5 work-related injures per 1000 farms or, alternatively, 4.3 work-related injuries per 1000 working youth. These numbers both represent a decline in the rate of injury per farm and per working youth over the past decade. 
Table 2: Work and Non-Work Injuries of Youth on U.S. Farms, 2009

\begin{tabular}{|l|l|l|l|}
\hline Age & \# of Farm (Non-Work) Injuries & \# of Farm (Work-Related) Injuries & Total \\
\hline $\mathbf{0 - 9}$ & 3590 & 510 & 4,110 \\
\hline $\mathbf{1 0 - 1 5}$ & 5570 & 1340 & 6,910 \\
\hline $\mathbf{1 6 - 1 9}$ & 2810 & 1340 & 4,150 \\
\hline Total & $\sim 12,690$ & $\sim 3190$ & $\sim 15,170^{*}$ \\
\hline
\end{tabular}

*Note: This number differs slightly from the overall injury total of 15,876 reported by NASS, likely due to some injuries not being reported with an age. All numbers in this table were calculated from percentages and/or absolute numbers listed in the April 24, 2012 NASS Report, Agriculture Safety: 2009 Injuries to Youth on Farms. Numbers in this table have been rounded to the nearest 10 due to minor discrepancies.

\section{The Current Regulation vs. the Proposed Regulation}

The current Hazardous Occupation Orders for agriculture, set in place over 40 years ago, allow agriculture to be the only industry where the permissible age for hazardous tasks is 16 years old as opposed to the national standard of 18 years of age (Leppink, 2011). One of the major goals of this proposed rule was to establish parity in the Hazardous Occupation Orders between the agricultural and non-agricultural sectors. Paradoxically, agriculture remains one of the most hazardous industries for people of all ages (Frank, 2006; CDC, 2012), yet it continues to operate under less stringent child labor laws than the non-agricultural sectors (McGinnis, 2011).

To create parity, the DOL proposed a variety of changes to the current regulations, including revising current agricultural hazardous orders, adding two new non-agricultural hazardous orders, and changing several age limit revisions. Some of the age limit changes focused on changing jobs previously allowed for $16+$ year-olds to 
18+year-olds only. Other age limit changes were also proposed for changing tasks currently allowed to be completed by 14 - and 15 -year olds to an age limit of $16+$. Specific changes proposed raising the age for participation in tobacco farming to 16 , raising the age for operating any power-driven equipment to 16 (with some limited exceptions for educational purposes), strengthening regulations prohibiting participation in pesticide handling, animal husbandry, timber operations, and tasks involving manure pits or grain bins. Furthermore, it would create a new hazardous order to prohibit youth under 18 from involvement in the storing, marketing and transporting of farm product raw materials, thereby barring all youth under 18 from working at grain elevators, stockyards, feedlots, auction yards, silos and grain bins. Finally, it would make it illegal for youth in both agricultural and non-agricultural work settings to utilize any electronic devices, for example cell phones, devices that access the internet, non-preprogrammed GPS, etc., while operating power driven machinery. For a much closer look at the regulatory changes please see Table 3. (76 FR 54835)

Table 3: An Overview of the Current Regulation versus the Proposed Regulation

\begin{tabular}{|c|c|c|}
\hline Task & $\begin{array}{l}\text { Age Requirement for Participating } \\
\text { in Task under Current Regulation }\end{array}$ & $\begin{array}{l}\text { Age Requirement for Participating in } \\
\text { Task under Proposed Regulation }\end{array}$ \\
\hline $\begin{array}{l}\text { Nonhazardous Work } \\
\text { Consent for 12-13 } \\
\text { year olds }\end{array}$ & $\begin{array}{l}\text { Currently allowed for non-school } \\
\text { hours at places exempt from } \\
\text { minimum wage standards by the } \\
\text { FLSA with the "consent" of a parent }\end{array}$ & $\begin{array}{l}\text { Changes "consent" to clearly say } \\
\text { "written consent" and updates cross- } \\
\text { references between sup-parts of the } \\
\text { proposal }\end{array}$ \\
\hline $\begin{array}{l}\text { Operating a Tractor } \\
\text { of Over } 20 \text { PTO } \\
\text { Horsepower, or } \\
\text { Connecting or } \\
\text { Disconnecting an } \\
\text { Implement (29 CFR } \\
570.71(a)(1))\end{array}$ & $\begin{array}{l}\text { Prohibited those under } 16 \text { when } \\
\text { tractor is over } 20 \text { PTO horsepower } \\
\text { with an exemption for } 14 \text { and } 15 \text { year } \\
\text { olds in a training program. The } \\
\text { current rule and proposal specifically } \\
\text { mention } 4 \text {-H as a currently } \\
\text { appropriate certification/ training } \\
\text { program for } 14-15 \text { year olds }\end{array}$ & $\begin{array}{l}\text { Removes } 20 \text { PTO threshold; Adds } \\
\text { stipulations including: licensing for } \\
\text { driving on road, no passengers, and } \\
\text { strict rules on 14- and } 15 \text {-year-old } \\
\text { educational exemption: tractors must } \\
\text { have seatbelt, rollover protection, and } \\
\text { student must have specific instruction } \\
\text { of at least } 90 \text { hours in a school setting }\end{array}$ \\
\hline
\end{tabular}




\begin{tabular}{|c|c|c|}
\hline $\begin{array}{l}\text { Operating or } \\
\text { Assisting with } \\
\text { Power-Driven } \\
\text { Machinery }(29 \text { CFR } \\
570.71(a)(2), 29 \text { CFR } \\
570.71(\text { a })(3) \text { and } 29 \\
\text { CFR } 570.71(\text { a)(7); } \\
\text { Proposed as } 29 \text { CFR } \\
570.71(\text { a })(2))\end{array}$ & $\begin{array}{l}\text { Prohibited by those under } 16 \text { for a } \\
\text { specific list of named machines with } \\
\text { an exemption for } 14 \text { and } 15 \text { year olds } \\
\text { in a training program; Permits those } \\
\text { under } 16 \text { to drive a bus, automobile, } \\
\text { or truck on public roads with no } \\
\text { passengers }\end{array}$ & $\begin{array}{l}\text { Combines three disparate HOs into one } \\
\text { new order for all power driven } \\
\text { machinery (except tractors); Prohibits } \\
\text { those under } 16 \text { from operating ALL } \\
\text { power-driven machinery with a very } \\
\text { strict exemption for select machines for } \\
\text { student-learners; Adds licensing } \\
\text { stipulations; Prohibits those under } 16 \\
\text { from riding as passengers on power- } \\
\text { driven machines }\end{array}$ \\
\hline $\begin{array}{l}\text { Occupations } \\
\text { involving the } \\
\text { operation of non- } \\
\text { power-driven } \\
\text { hoisting apparatus } \\
\text { and conveyors } \\
\text { (Proposed as } 29 \text { CFR } \\
570.72(b)(3))\end{array}$ & Not prohibited currently & $\begin{array}{l}\text { Recommendation of new Ag HO: } \\
\text { Prohibits those under } 16 \text { from using } \\
\text { non-power-driven hoisting apparatus } \\
\text { and conveyors }\end{array}$ \\
\hline $\begin{array}{l}\text { Certain occupations } \\
\text { involving working } \\
\text { with or around } \\
\text { animals }(29 \text { CFR } \\
570.72(\text { b) }(4))\end{array}$ & $\begin{array}{l}\text { Prohibited by those under 16; } \\
\text { Applies to working in a yard, pen, or } \\
\text { stall occupied by a: bull, boar, or stud } \\
\text { horse, or sow with suckling pigs, or } \\
\text { cow with newborn calf }\end{array}$ & $\begin{array}{l}\text { Keeps current restrictions and prohibits } \\
\text { several additional activities including: } \\
\text { working with animal(s) during any } \\
\text { activity that may inflicts pain on said } \\
\text { animal(s), working with an animal } \\
\text { known to be dangerous, cooping } \\
\text { poultry for slaughter, herding animals } \\
\text { in confined areas or by ATV, truck, or } \\
\text { horseback with no learner exemption }\end{array}$ \\
\hline $\begin{array}{l}\text { Felling, Bucking, } \\
\text { Skidding, Loading, } \\
\text { or Unloading Timber } \\
\text { With Butt Diameter } \\
\text { of More Than Six } \\
\text { Inches }(29 \text { CFR } \\
570.71(a)(5))\end{array}$ & $\begin{array}{l}\text { Prohibited by those under } 16 \text { for } \\
\text { timber of more than } 6 \text { inches in } \\
\text { diameter }\end{array}$ & $\begin{array}{l}\text { Removes the six inch diameter } \\
\text { threshold, keeps age limit at } 16 \text {, and } \\
\text { therefore prohibits all minors under } 16 \\
\text { from felling, bucking, skidding, } \\
\text { loading, or unloading any timber. }\end{array}$ \\
\hline $\begin{array}{l}\text { Working From a } \\
\text { Ladder or Scaffold at } \\
\text { a Height of Over } 20 \\
\text { Feet }(29 \text { CFR } \\
570.71(\text { a })(6)) \\
(\text { Proposed as } 29 \text { CFR } \\
570.99(\text { b) }(6) ; \\
570.99(b)(7) ; 570.66 ;\end{array}$ & $\begin{array}{l}\text { Prohibited those under } 16 \text { from } \\
\text { working at a height over } 20 \text { feet in } \\
\text { order to: paint, make repairs, } \\
\text { building structures, prune trees, } \\
\text { picking fruit, etc. }\end{array}$ & $\begin{array}{l}\text { Expands HO to cover work on: roofs, } \\
\text { silos, grain bins, windmills, towers, } \\
\text { vehicles, machines, and implements; } \\
\text { Reduces height limit from twenty feet } \\
\text { to six feet; Splits HO into two new ag } \\
\text { HOs: HO } 6 \text { for agricultural } \\
\text { construction activities and HO } 7 \text { for } \\
\text { work at a height of over } 6 \mathrm{ft} \text {. Also adds }\end{array}$ \\
\hline
\end{tabular}




\begin{tabular}{|c|c|c|}
\hline 570.68$)$ & & $\begin{array}{l}\text { two new non-ag HOs: HO } 15 \text { for } \\
\text { excavation occupations and HO } 17 \text { for } \\
\text { non-ag construction occupations; } \\
\text { Clarifies definition of roof in HO } 16\end{array}$ \\
\hline $\begin{array}{l}\text { Working Inside a } \\
\text { Fruit, Forage, or } \\
\text { Grain Storage Bin, a } \\
\text { Silo, or a Manure Pit } \\
(29 \text { CFR } \\
570.71(\text { a })(8))\end{array}$ & $\begin{array}{l}\text { Currently prohibited for all youth } \\
\text { under } 16\end{array}$ & $\begin{array}{l}\text { Clarifies to add emphasis on } \\
\text { prohibiting all work in these settings. } \\
\text { Changes the waiting period of two- } \\
\text { weeks after adding new silage has been } \\
\text { added to no entry at any time. Asks for } \\
\text { input on whether this HO should be } \\
\text { changed to include any confined space } \\
\text { (such as livestock barns), Proposed as } \\
\text { Ag HO } 8 \text { (confined spaces) and HO } 9 \\
\text { (manure pits); not learner exempt. }\end{array}$ \\
\hline $\begin{array}{l}\text { Handling or } \\
\text { applying agricultural } \\
\text { chemicals classified } \\
\text { as Category I or II } \\
\text { Toxicity }(29 \text { CFR } \\
570.71(\text { a })(9))\end{array}$ & $\begin{array}{l}\text { Only prohibits those under } 16 \text { from } \\
\text { working with Category I or II } \\
\text { toxicity pesticides (acutely toxic } \\
\text { chemicals) }\end{array}$ & $\begin{array}{l}\text { Updates HO to reflect EPA worker } \\
\text { protection recommendations for } \\
\text { pesticides to address chronic (not only } \\
\text { acute) exposure hazards; Proposed as a } \\
\mathrm{Ag} \mathrm{HO} 10 \text { and prohibits all handling of } \\
\text { pesticides with no learner exemptions }\end{array}$ \\
\hline $\begin{array}{l}\text { Handling or using a } \\
\text { blasting agent ( } 29 \\
\text { CFR 570.71(a)(10)) }\end{array}$ & Prohibited under age 16 & $\begin{array}{l}\text { Retains prohibition, renames as } \mathrm{Ag} \mathrm{HO} \\
11 \text { and confirms there will be no } \\
\text { student learner exemption }\end{array}$ \\
\hline $\begin{array}{l}\text { Transporting, } \\
\text { transferring, or } \\
\text { applying anhydrous } \\
\text { ammonia }(29 \text { CFR } \\
570.71(\text { a })(11))\end{array}$ & Prohibited under age 16 & $\begin{array}{l}\text { Retains prohibition, renames as } \mathrm{Ag} \mathrm{HO} \\
12 \text { and confirms there will be no } \\
\text { student learner exemption }\end{array}$ \\
\hline $\begin{array}{l}\text { Employment in } \\
\text { Tobacco Production } \\
\text { and Curing } \\
(\text { Proposed as } \\
570.99(b)(13))\end{array}$ & $\begin{array}{l}\text { Not prohibited currently; } 14 \text { and } 15 \\
\text { year olds may participate in all } \\
\text { aspects of tobacco farming }\end{array}$ & $\begin{array}{l}\text { Recommendation of new Ag HO: Ban } \\
\text { all work related to tobacco farming, } \\
\text { including planting, cultivating, topping, } \\
\text { harvesting, baling, barning, and curing. } \\
\text { Proposed as HO } 13 \text { with no student } \\
\text { learner exemption }\end{array}$ \\
\hline $\begin{array}{l}\text { Employment Under } \\
\text { Adverse Conditions } \\
\text { (Under consideration } \\
\text { with no proposed FR } \\
\text { number citation) }\end{array}$ & Not prohibited currently & $\begin{array}{l}\text { Recommendation of new non-ag HO: } \\
\text { Prohibit youth under } 16 \text { from working } \\
\text { in conditions above or below certain } \\
\text { temperatures factoring in other weather } \\
\text { conditions including wind/humidity; } \\
\text { Limit number of hours in direct sun }\end{array}$ \\
\hline
\end{tabular}




\begin{tabular}{|c|c|c|}
\hline $\begin{array}{l}\text { Child Labor } \\
\text { Exemptions } \\
\text { Applicable to } \\
\text { Agricultural } \\
\text { Employment (29 } \\
\text { CFR 570.123) }\end{array}$ & Statutory exemption & $\begin{array}{l}\text { Parental Exemptions are statutory, so } \\
\text { changes cannot be made without } \\
\text { Congressional approval. The DOL, } \\
\text { however, proposed to "clarify" the } \\
\text { terms "parent," "operated by," } \\
\text { "agriculture," "school hours," and } \\
\text { "employer;" See Appendix A. }\end{array}$ \\
\hline $\begin{array}{l}\text { Employment in } \\
\text { farm-product raw } \\
\text { materials wholesale } \\
\text { trade industries } \\
\text { (Proposed as } 29 \text { CFR } \\
570.69 \text { ) }\end{array}$ & Not prohibited currently & $\begin{array}{l}\text { Recommendation of new non-ag HO: } \\
\text { Prohibits the employment of any youth } \\
\text { under } 18 \text { in any of the wholesale raw } \\
\text { materials industries, including } \\
\text { stockyards, grain elevators, livestock } \\
\text { auctions, feedlots, etc. }\end{array}$ \\
\hline $\begin{array}{l}\text { Using electronic } \\
\text { devices or comm. } \\
\text { devices, while } \\
\text { operating/assisting to } \\
\text { operate power-driven } \\
\text { equipment (Proposed } \\
\text { as } 29 \text { CFR } \\
570.71(\text { a) }(19))\end{array}$ & Not prohibited currently & $\begin{array}{l}\text { Recommendation of new non-ag HO: } \\
\text { Prohibits the uses of electronic devices } \\
\text { while operating power-driven devices } \\
\text { including talking on cellphones, using } \\
\text { any device that accesses the internet, } \\
\text { entering data into a GPS, performing } \\
\text { any administrative function, etc. Cells } \\
\text { are allowed to call } 911 \text { and radios/ipods } \\
\text { may be listened to in hands-free mode. }\end{array}$ \\
\hline $\begin{array}{l}\text { Child labor } \\
\text { violations-Civil } \\
\text { Money Penalties (29 } \\
\text { CFR 579) }\end{array}$ & $\begin{array}{l}\text { Includes detailed descriptions of the } \\
\text { monetary penalties incurred for } \\
\text { violations of the child labor } \\
\text { regulations set forth by the rule. }\end{array}$ & $\begin{array}{l}\text { Updates the civil money penalties to } \\
\text { match the provisions of the WHD's } \\
\text { Field Assessment Bulletin 2010-, adds } \\
\text { "additional transparency" methods, re- } \\
\text { numbers and organizes sections }\end{array}$ \\
\hline
\end{tabular}

Although the Department of Labor consistently maintained that the proposed rule would affect only hired workers and in no way compromise the statutory parental exemption that enables children of any age to work on their parents' farms, this point proved to cause some of the most contention during the rulemaking process (Alexander, 2012). The parental exemption statute reads "children of any age who are employed by their parent, or a person standing in the place of a parent, to perform any job on a farm owned or operated by their parent or such person standing in the place of a parent" (29 
CFR 570.123). Within the proposal submitted to the Federal Register, the DOL spends a significant amount of space discussing the parental exemption, specifically focusing on their inability to change the statute but desire to clarify its meaning in the new rule (FR 76:171, 54841) (see Appendix A for the language used in the proposal). The DOL notes the broad way in which the parental exemption has been interpreted in the past and firmly asserts a broad interpretation of "parental" was not intended by Congress (FR 76:171, 54841).

Even within the official language of the proposed rule submitted to the Federal Register, the exemption and the DOL's interpretation and clarification leaves the reader with some confusion, at times focusing on their desire to narrow the interpretation and then at other times assuring that due to its statutory nature they cannot and will not change the parental exemption. For example, in the first paragraph of the proposal printed in Volume 76 Number 71 of the Federal Register on page 54836, the Department of Labor clearly states, "The proposed agricultural revisions would impact only hired farm workers and in no way compromise the statutory child labor parental exemption involving children working on farms owned or operated by their parents." However, as aforementioned the parental exemption is discussed at length several times within the proposal. On page 54866, it states "The Department proposes to clarify the parental exemption involving agricultural employment...[with]...guidance as to who qualifies as a parent; what determines that a farm is 'operated by' a parent; and how the Department interprets the extension of this parental exemption to persons standing in the place of a 
parent as well as a relative who may take temporary custody of a youth and stands in the place of the parent."

While the formal language of the regulation is what truly matters from a legal standpoint, a review of the informal DOL news releases and related online informational announcements also leaves a fair deal of uncertainty as to how the DOL intended the public to interpret the parental exemption. An August 2011 news release lists only "children working on farms owned by their parents" (McGinnis, 2011), possibly implying sole parental ownership with no exemption for parental operation. The October 2011 Request for Comment in the Federal Register and corresponding communications materials lists a slightly more expanded interpretation of the parental exemption with "children working on farms owned or operated by their parents" (Leppink, 2011), no longer implying sole ownership and including farms simply "operated” by parent(s), which is closer to the language actually used in the regulation. Even after the broadening of the interpretation in the October press release, considerable media attention and grassroots participation still focused on how the new "clarification" of the statutory parental exemption could impact children working on farms on which they lived.

Ownership of modern farms may be classified in a number of different ways. They may be classified as a sole ownership, a partnership, a limited liability corporation, or a corporation. Additionally, under the current regulation's interpretation of the parental exemption, youth who are close relatives of a farmer may also currently work on farms if the owner/operator of the farm (i.e. their close relative) is standing in place of the youth's parent during the hours of work. It was unclear in both the proposed regulation and 
associated DOL media releases how and if the future interpretation of the parental exemption would affect children working on farms that were not solely owned by their parent or children living and working on farms that were not solely owned by a relative. It is clear in the regulation that although the parental exemption is statutory, the DOL desired to narrow its interpretation and address the changing ownership trends of modern farms. The DOL cites the desire for this clarification in the proposal, writing: "only the owner or operator of a farm is in a position to regulate the duties of his or her child and provide guidance. Where the ownership or operation of the farm is vested in persons other than the parent, such as a business entity, corporation or partnership (unless wholly owned by the parent(s)), the child worker is responsible to persons other than, or in addition to, his or her parent, and his or her duties would be regulated by the corporation or partnership, which might not always have the child's best interests at heart" (FR 76:171, 54841). This line fed much of the contention.

It is not until the February 2012 News Release that the DOL begins to address the concerns by stakeholders that the clarification of the parental exemption in the proposal may have been too unclear and/or restrictive. In the February 2012 news release, the DOL announced its intent to rewrite the parental exemption interpretation within the proposal and its intent to request another comment period to address the re-proposal of the parental exemption (Alexander, 2012). It also assured until the final rule that the interpretation of the parental exemption would remain in its broader "as-is" state, with part-owners and even corporations being allowed (McGinnis, 2012). However before the DOL's re-proposal of the parental exemption interpretation came to fruition, it was 
announced in April 2012 that the entire proposal was withdrawn, including the new wording of the parental exemption (Lamont, 2012). One reason listed for the withdrawal was concerns over the parental exemption (Alexander, 2012). No further attention has been given to the parental exemption from a regulatory perspective since the entire proposal was withdrawn, although the DOL has announced its intention to include the public in developing non-regulatory education based children's agricultural safety interventions in the future (Lamont, 2012).

Non-regulatory education based interventions are also the planned method for addressing the other aspects of the proposal, in addition to the aforementioned parental exemption. While the entire proposal was withdrawn, the DOL must still contend with the high injury and fatality rate for children in agriculture and the other related factors that instigated the development of the proposal initially. The announcement that the DOL plans to remain committed to improving children's agricultural safety, albeit in the non-regulatory sphere, is one of the many reasons why an analysis of the 10,325 comments remains important even after the proposed rule withdrawal. The stakeholder comments along with other forms of public participation can help the DOL develop a bottom-up participatory process to create effective educational recommendations that are met with less controversy than the regulatory proposal was. Furthermore, this analysis has value from a public participation research standpoint. It provides insight into public participation one of the most commented upon regulatory proposals of 2012; public participation in this rule is discussed further below. 


\section{Public Participation Opportunities in this Proposed Rule}

On September 2, 2011, the DOL's Wage and Hour Division requested interested parties to submit written comments by November 1, 2011 (6 FR 54835). During this initial comment period, the DOL's Wage and Hour Division announced that a public hearing would also be held on the NPRM (76 FR 61289). Agencies do not need to hold public hearings in informal rulemaking unless the agency decides a hearing is warranted due to high levels of public interest or other extenuating circumstances. Parties interested in giving oral testimony at the October 11, 2011 hearing in Tampa, Florida had to submit notice of their intent to speak at the hearing by October 5 .

On October 26, 2011, Deputy Administrator of the Wage and Hour Division Nancy Lippink announced that due to significant requests from members of Congress and various agricultural business organizations, including the National FFA Organization, American Farm Bureau Federation and National Association of State Departments of Agriculture, the initial comment period would be extended to December 1, 2011 (76 FR 67104). A DOL News Release in February 2012 announced an additional comment period would be forthcoming. A re-proposal of the rule would focus on addressing the "parental exemption" and the impacts the interpretation of the exemption would have on "rural tradition." The DOL said in the news release, "following the president's historic executive order [13563] on regulation, issued in January 2011, this re-proposal reflects the department's careful attention to public comments and its conclusion that it is appropriate to provide the public with further opportunities to participate in the regulatory process" (Alexander, 2012). 
Although, the DOL indicated that a second comment period would follow within the next months, the next news release and corresponding Federal Register submission (77 FR 31549) announced the withdrawal of the proposed rule instead of a new comment proposal (Lamont, 2012). The press release included a statement that again emphasized federal commitment to public participation, which read "the Obama administration is also deeply committed to listening and responding to what Americans across the country have to say about proposed rules and regulations" (Lamont, 2012). Although the DOL lists several forms of stakeholder involvement the agency utilized to gain public perspective before the release of the proposal, many argued that the DOL had not utilized enough stakeholder involvement, particularly from the farm-related stakeholders, prior to drafting the proposal.

\section{Summary of Chapter One and Outline of Thesis}

This chapter has outlined the federal agency rulemaking process and described how written comments allow the public to participate in rulemaking across all federal agencies. After describing the general rulemaking process, specific focus was given to the history of children's agricultural safety at the federal level in the United States. This brief history included both non-regulatory and regulatory approaches to improving children's agricultural safety and focused particularly on the regulatory actions of the Department of Labor's Wage and Hour Division and the non-regulatory actions of the NOISH. On the regulatory side, the last major update occurred through a rule enacted in 1966 . On September 2, 2011, the U.S. Department of Labor (DOL) announced through an NPRM in the Federal Register its intent to revise child labor regulations for agriculture. The 
NPRM cites relatively high levels of youth fatalities — over 100 per year — and numerous injuries in the agricultural sector as a major reason for the development of the DOL's proposal (29 CFR 570).

To gain a better understanding of the proposal and its changes to the FLSA and HOs, the September 2011 proposed rule was briefly compared and contrasted with the current version of children's ag safety FLSA and HO rules. An initial comment period of 60 days was extended once to December 1, 2011 and ultimately garnered over 10,000 comments to the Federal Register over the entire comment period. Then, the DOL announced in February 2012 its intentions to revise the proposal and ask for another set of comments, but ultimately withdrew the proposal in April 2012, deciding instead to focus more on non-regulatory actions.

The 10,325 comments received in response to the proposed changes to the hazardous orders for agriculture within the FLSA form the basis of the analysis in this thesis. Chapter 2 describes the methodology used to analyze the content of the written comments submitted by stakeholders to the federal register. A sample of 1000 comments was selected randomly from the 10,325 comments submitted. NVivo content analysis software was utilized to organize qualitative characteristics of the 1000 sample comments, including, if discernible, stakeholder groups, the most common themes addressed in the comments, and the varying levels of support or concern for the proposal. Additionally, when discernible, whether the author was a minor was recorded. The methodology design fits the goal of answering the major research questions of this thesis: 1) to what extent did an individuals' stakeholder group predict the individual's degree of 
support for the proposal, and 2) what aspects of the proposed regulation, if any, caused the most contention. Before addressing the results, Chapter 2 concludes with a discussion of the major limitations of the research design and implementation within this thesis.

Chapter 3 presents the results of the NVivo content analysis. NVivo allows comments to be coded electronically with descriptive labels that can be sorted and organized easily via the software. Each comment was coded for the stakeholder group, the major themes addressed in the letter, and the degree of support for the proposal. Major stakeholder groups identified include 1) Previous Farm Residents; 2) Current Farm Residents; 3) Non Farm Residents with Identified Farm Employment Connections; 4) Children's Safety Experts; 7) Agricultural Educators; 8) Governmental Organizations; 9) Farm Bureau;10) Other Non-Governmental Organizations; 11) Other Stakeholders and 12) Unidentified. Major themes addressed in each letter of the sample were also coded and identified. Each theme and the number of comments that contained that theme are discussed briefly. Examples from the comments in the form of "typical" quotes addressing each theme are also given. Finally, the pattern of linkage between each comment submitter's identified stakeholder group and each comment submitter's degree of support is presented.

Chapter 4 discusses and interprets the results of the comment analysis, which were presented in Chapter 3. The discussion focuses on broader impacts of the results beyond this thesis. These broader impacts include: 1) the impact of public participation on the results of rulemaking; 2) bottom-up approaches to rulemaking and bottom-up 
approaches to non-regulatory improvements; and 3) next steps in continuing this research. 


\section{CHAPTER 2: METHODOLOGY}

The previous chapter concentrated on introducing the topic of children's agricultural safety within both a historical context and a current regulatory context. By the December 1, 2011 comment period close, over 10,325 submissions had been posted regarding the DOL's NPRM for “Child Labor Regulations, Orders and Statements of Interpretation: Violations-Civil Money Penalties" (RIN: 1235-AA06). This chapter enumerates the methodology utilized to carry out a qualitative analysis on a sample of 1000 randomly selected comment submissions.

This chapter begins with a description of the research methods and design of this thesis. It describes the process of determining the sample size, the procedure for randomly selecting the sample, and the method for analyzing the1000 comments in the sample with NVivo software. Next, it describes the formation of the research questions and how the results of the NVivo qualitative analysis were utilized to answer those questions. This chapter concludes with a focus on the limitations of this study.

\section{Research Design and Methods}

The data, or total population size, for this thesis are the 10,325 comments submitted to the Federal Register in response to the DOL's Wage and Hour Division's NPRM for "Child Labor Regulations, Orders and Statements of Interpretation: Violations-Civil Money Penalties” (RIN: 1235-AA06) (29 CFR 570). All comments submitted — whether electronically or hardcopy via traditional mail — to the DOL through the informal rulemaking process are posted to the Federal Register on the website Regulations.gov: Your Voice in Federal Decision-Making. Comments become part of the 
permanent record in the Federal Register on the Regulations.gov site and are publically accessible through that website at any time. The comments for this NPRM are available at http://www.regulations.gov /\#!docketBrowser; $\mathrm{dct}=\mathrm{PS} ; \mathrm{rpp}=100 ; \mathrm{so}=\mathrm{ASC} ; \mathrm{sb}=\mathrm{docId} ; \mathrm{po}=0 ; \mathrm{D}=\mathrm{WHD}-2011-0001$.

Comments varied in length. Comments range from a few words from an individual citizen to a formal research study with multiple journal article attachments composed by a children's safety research center to a large scale petition with thousands of signatures compiled by an advocacy organization. Regardless of the size of the submission, classification of the comment remains consistent. On Regulations.gov and within this thesis each singular submission (of any size) that was assigned its own unique federal register ID number is counted as one "unique" comment. Using this consistent classification, there are 10,325 comments listed on Regulations.gov as "unique" public submissions for this NPRM. This does not mean each comment contains unique information, but rather that 10,325 uniquely identified and labeled submissions occurred during the comment period. There was repetition within comments due to the submission of form letters. Regardless of repetition, these 10,325 comments comprise the total population group in this study. From this total population of 10,325, 1000 comments were selected randomly to form the sample group.

A sample size of 1000 comments was chosen for several reasons. It was small enough to manage within the time constraints of this research, but large enough to be statistically representative of the total population. A 1000 comment sample selected randomly from a total population of 10,325 results in a 95 percent confidence level with a 
\pm 3 percentage point confidence interval. Any quantitative results compiled from the analysis of the sample can be applied to the total population with 95 percent confidence that the results fall within a range of plus or minus three percentage points of the sample statistics.

Utilizing the $=\mathrm{RAND}()$ function in Microsoft Excel to assign random numbers to the population helped ensure the validity of the random sample selection. To select the 1000 comment sample, the10,325 comments of the entire population were downloaded in a Microsoft Excel file prepared by the Federal Register; this Excel file is available as direct download from Regulations.gov. The information listed in the Federal Register's Excel file includes each comment's Federal Register ID, time and date of submission, time and date of the online posting, author's first and last name (as provided), and own unique URL. Within the Excel file, a blank column was added. This new column was labeled "Randomized Numbers," and then the $=\mathrm{RAND}()$ function was applied to the column. This gave each cell in the column a completely random number assignment. These cells, with their random number assignments, each corresponded to one of the 10,325 rows - the 10,325 comments that made up the total population. Using the "Sort" command, the "Randomized Numbers" column was sorted from smallest to largest number.

This sorting method meant that the comments were ordered in a completely random fashion, and the first 1000 comments (rows 1-1000) were selected to form the random 1000 comment sample needed for analysis. Comments selected as the random sample (rows 1001-10,325) were not read or analyzed in this thesis and were discarded. 
A variety of universities and research institutions, including Iowa State University and the University of Wisconsin-Eau Claire, describe on their websites this method for creating a random sample with Excel (Vardeman, 2008; Miller, 2011). The step-by-step instructions on their websites ensured the correct process was followed during the sample selection phase.

The actual text portion of each comment was not contained in the Federal Register's Excel file downloaded from Regulations.gov. The Federal ID numbers of the comments in the randomly selected sample within Excel were used to identify each of the 1000 text portions of the comments to include in the sample from the overall population of 10,325 listed on the website. Each of the 1000 text portions of the random sample were then individually downloaded from the 10,325 comments posted on Regulations.gov and (re)labeled. The majority of the text portions of the sample comments were HTML format typed directly into the text box on Regulations.gov. About 10 percent of the comments were not HTML text and were submitted as electronic attachments or as scans of hardcopy letters sent through traditional mail. For consistency, each HTML file was converted to a .doc file and renamed with its Federal ID number. Each of the non-HTML attachments was also renamed with its Federal ID number. Once the 1000 comments were consistently labeled and saved individually, the 1000 files were imported to NVivo.

NVivo 10 Content Analysis Software by QSR International functioned as the software based analysis method in this thesis. NVivo was selected for its ability to organize large amounts of qualitative data, easily search and code text, and perform cross-categorical analysis. NVivo enables imported files to be coded with researcher 
identified themes and classifications. Each of the 1000 comments was coded within each of the following categories: 1) stakeholder group; 2) the degree of support for the proposal; 3) the major issues/concerns (themes) addressed within the comment; and 4) if discernible, whether the author was a child under the age of 18 and/or if the letter was a form letter. The stakeholder group and theme categories were developed iteratively after an initial reading of the sample and a literature review. This ensured a bottom-up approach to the coding. The distributions of the codes and the coding relationships between the three above categories were then analyzed. The next section of this chapter addresses how and why this methodology was developed and employed to answer the questions posed by this thesis.

\section{Research Questions}

This thesis seeks to answer the following research questions: 1) to what extent did an individuals' stakeholder group predict the individual's degree of support for the proposal, and 2) what aspect of the proposed regulation, if any, caused the most contention. To answer these questions each comment was coded in three different major categories. These three major categories, called "nodes" in NVivo, include stakeholder group, degree of support, and theme. In addition to the three major node categories, comments were also marked if they were discernibly written by a child or if they were a "form" letter. All 1000 comments within the sample were individually coded. After the 1000 comments were coded within each of the nodes, cross category analysis was utilized to identify informal linkages between the sub-categories of the nodes. Intra-category 
analysis allowed the most common codes assigned within the node to be identified.

Results and a discussion of the results are addressed in the following chapters.

Within two of the overall nodes/categories, each comment could only be assigned one code. Put another way, under the stakeholder group node and the degree of support node, each code was mutually exclusive. For example, a comment's author could not belong to more than one stakeholder group. Descriptions of each stakeholder group were developed to be exclusive (see Table 4: Stakeholder Groups). A comment's author could not be a current farm resident and a previous farm resident at the same time. Or, in the other mutually exclusive category, a comment's author could only convey one level of support (see Table 5: Degree of Supports). For example a comment could not be both in favor of the regulation and neutral towards the regulation. Each comment could only be coded under one of the levels of support: in favor, against, mixed or neutral.

Table 4: Stakeholder Groups (Mutually Exclusive Codes)

\begin{tabular}{|l|l|}
\hline Name of Stakeholder & Description \\
Unidentified & $\begin{array}{l}\text { Includes any comment submitted by an individual that does not } \\
\text { discernibly identify within the letter as belonging to a specific } \\
\text { stakeholder group or does not fit within any of the other stakeholder } \\
\text { groups listed below. }\end{array}$ \\
\hline Former Farm Residents & $\begin{array}{l}\text { Includes those who identify themselves as previous residents of } \\
\text { farms, i.e. former "farm kids", "born and raised", etc. This } \\
\text { stakeholder group does not include those who still live on farms } \\
\text { (see Current Farm Residents). }\end{array}$ \\
\hline Current Farm Residents & $\begin{array}{l}\text { Includes those who identify themselves as current residents of } \\
\text { farms. }\end{array}$ \\
\hline
\end{tabular}




\begin{tabular}{|c|c|}
\hline $\begin{array}{l}\text { Non-Farm Residents, Self- } \\
\text { Identified Direct Farm } \\
\text { Employment Connection }\end{array}$ & $\begin{array}{l}\text { Includes those who do not identify themselves as previously or } \\
\text { currently living on a farm, but do identify either themselves or their } \\
\text { immediate family (i.e. their child(ren)) as being employed in ag. }\end{array}$ \\
\hline (Children's) Safety Expert & $\begin{array}{l}\text { Includes any submission in which the author identifies or self- } \\
\text { describes themselves as a children's safety expert/researcher/ } \\
\text { professional. Any submission that meets this description but is } \\
\text { from a governmental organization or official would be excluded } \\
\text { from this category and coded under "Governmental Organization." }\end{array}$ \\
\hline I Educator & $\begin{array}{l}\text { Includes any submission in which the author identifies themselves } \\
\text { as an Agricultural Instructor/Teacher, even if the author also } \\
\text { identifies being a part of another stakeholder group, i.e. previous } \\
\text { farm resident or current farm resident. }\end{array}$ \\
\hline Gove & $\begin{array}{l}\text { Includes all comments submitted by a domestic (local, state, or } \\
\text { national) or international governmental group or a member of } \\
\text { Congress. }\end{array}$ \\
\hline $\begin{array}{l}\text { Farm Bureau } \\
\text { Organization }\end{array}$ & $\begin{array}{l}\text { Includes only official county, state, or national Farm Bureau } \\
\text { submissions. Farm Bureau is national farm organization with } \\
\text { farmer membership. Does not include singular farmers who simply } \\
\text { identify themselves as members of a Farm Bureau but do not list } \\
\text { themselves as writing on official behalf of any level of the org. }\end{array}$ \\
\hline $\begin{array}{l}\text { Other Non-Governmental } \\
\text { Organizations }\end{array}$ & $\begin{array}{l}\text { Includes only letters written on behalf of an organization or group. } \\
\text { May not include letters written with any governmental affiliation or } \\
\text { any Farm Bureau affiliation. }\end{array}$ \\
\hline
\end{tabular}

Table 5: Degree of Support (Mutually Exclusive Codes)

\begin{tabular}{|l|l|}
\hline Degree of Support & Description \\
\hline Against & Comment indicated a strong opinion against the proposal. \\
\hline In Favor & Comment indicated favorable support for the proposal. \\
\hline Mixed & $\begin{array}{l}\text { Comment indicated both positive and negative support towards the } \\
\text { proposal and/or contradictory remarks regarding support. }\end{array}$ \\
\hline Neutral & The comment does not indicate a position of support in any way. \\
\hline
\end{tabular}


The theme node was treated differently. Under the theme node, a comment could be tagged with multiple theme tags or could be tagged with none. Themes were developed after an initial reading of the comments. If a specific phrase, unique historical example, or particular area of concern arose in multiple comments from multiple authors, it was made into an individual code in the theme node (see Table 6). These codes facilitated the subsequent analysis of the comments. Because the codes were created after a preliminary reading of the data, the coding methodology follows a bottom-up theory and thematic analysis approach. Bottom-up theory involves creating theory after initial data exploration and throughout the data analysis (Gibson, 2009). This allowed the theme codes to evolve from the comment content and helped reduce bias from preconceived author theories about the comment data. Using bottom-up theory can reduce the possibility of an author interpreting and imposing ideas based on what the author thinks should be present within the data (Gibson, 2009). Thematic analysis is defined as a process of analyzing data according to "commonalities, relationships and differences across a data set" (Gibson, 2009).

Table 6: Themes Codes and Descriptions

\begin{tabular}{|l|l|}
\hline Theme & Description \\
\hline On-the-job Training & $\begin{array}{l}\text { Includes discussions related to youth needing on-the-farm training } \\
\text { in order to learn agricultural skills. This broad code also includes } \\
\text { references to this proposal leading to a reduction in skilled farmers } \\
\text { in the future due to a lack of farm exposure as youth and how safety } \\
\text { can be better taught on the job through hands-on learning. }\end{array}$ \\
\hline
\end{tabular}




\begin{tabular}{|c|c|}
\hline $\begin{array}{l}\text { Work Ethic and } \\
\text { Responsibility }\end{array}$ & $\begin{array}{l}\text { Includes any reference to farmwork creating a stronger work ethic } \\
\text { and developing more responsibility in comparison to other } \\
\text { activities; Includes reference to employers looking for this work } \\
\text { ethic, responsibility and life skills in farm kids. }\end{array}$ \\
\hline $\begin{array}{l}\text { Rural Tradition and } \\
\text { Lifestyle }\end{array}$ & $\begin{array}{l}\text { Includes any broad references to rural lifestyle, rural/ag culture, the } \\
\text { rural family structure, the tradition of families/neighbors/ } \\
\text { community/multiple generations working together. }\end{array}$ \\
\hline $\begin{array}{l}\text { Governmental Lack of } \\
\text { Understanding and } \\
\text { Disconnect }\end{array}$ & $\begin{array}{l}\text { Includes any comment which addresses a government disconnect, } \\
\text { references Washington/Congress/DOL as being “out-of-touch,” or } \\
\text { suggests the government doesn't understand, isn't thinking, is } \\
\text { absurd, ridiculous, crazy, foolish, etc. }\end{array}$ \\
\hline $\begin{array}{l}\text { Parental Exemption, } \\
\text { Definition }\end{array}$ & $\begin{array}{l}\text { Any reference to the "parental exemption;" the many different sizes } \\
\text { and legal classifications (LLC, Inc., etc.) of modern farms; or the } \\
\text { inability of grandparents, aunts, uncles to supervise own family. }\end{array}$ \\
\hline Over-Regulation & $\begin{array}{l}\text { Includes references to government overstepping boundaries; too } \\
\text { much bureaucracy; yet-another-regulation; or going "too-far" in } \\
\text { with this latest proposal. }\end{array}$ \\
\hline $\begin{array}{l}\text { Importance of } \\
\text { Child(ren)'s Safety }\end{array}$ & $\begin{array}{l}\text { Includes any reference to the importance of the safety of youth, } \\
\text { safety being the "number one concern," and/or the high } \\
\text { injury/fatality rate in youth agricultural workers. }\end{array}$ \\
\hline $\begin{array}{l}\text { 4-H and FFA Youth } \\
\text { Programs }\end{array}$ & $\begin{array}{l}\text { Includes references to the proposal's potential impact on } 4 \text {-H or } \\
\text { FFA programs; does not include any references to other youth } \\
\text { organizations. }\end{array}$ \\
\hline America and Its Role & $\begin{array}{l}\text { Includes references to the perceived role of America in feeding the } \\
\text { world; agriculture being the backbone of America; this rule hurting } \\
\text { America's future; farmers building/founding/leading this country; } \\
\text { youth being the future of this nation. }\end{array}$ \\
\hline $\begin{array}{l}\text { Small Farmer/Small } \\
\text { Business Impacts }\end{array}$ & $\begin{array}{l}\text { Includes references about the proposed regulation } \\
\text { disproportionately affecting small farmers, family farmers, or } \\
\text { small/family business owners more than large agribusiness entities. }\end{array}$ \\
\hline
\end{tabular}




\begin{tabular}{|c|c|}
\hline $\begin{array}{l}\text { Bad Habits of Today's } \\
\text { Youth }\end{array}$ & $\begin{array}{l}\text { Includes any negative comment that addresses the idea of youth } \\
\text { today being "lazy," "weak," "couch potatoes," or sitting inside too } \\
\text { much; includes any reference to having too much time to get into } \\
\text { trouble/steal/develop drug/alcohol habits; includes any comment } \\
\text { regarding excessive use of video games, internet, or television. }\end{array}$ \\
\hline Passion, Enjoyment & $\begin{array}{l}\text { Includes references to how children enjoy/love/have a passion for } \\
\text { working on the farm; the disappointment youth would have from } \\
\text { not working on the farm; how the work is more than a job for } \\
\text { youth: it's their favorite pastime/hobby and place to meet friends. }\end{array}$ \\
\hline Youth Finances & $\begin{array}{l}\text { Includes phrases/stories about youth paying for college/cars/ } \\
\text { computers/major purchases with earnings and/or about benefits of } \\
\text { youth earning own spending money; also includes comments about } \\
\text { winning money awards and college scholarships from the work. }\end{array}$ \\
\hline Bad Economy & $\begin{array}{l}\text { Includes any reference to the current unemployment rate, poor } \\
\text { economy, Great Recession, thankfulness/luckiness in finding any } \\
\text { jobs right now, and/or the low importance of this issue in } \\
\text { comparison to the economy/debt; includes references to how this } \\
\text { job will reduce number of total jobs available. This is subtly related } \\
\text { to the "Youth Finances" and "Only Available Job" categories. } \\
\text { Coding was carefully separated between the three. }\end{array}$ \\
\hline $\begin{array}{l}\text { (Only) Available Jobs in } \\
\text { Rural Areas }\end{array}$ & $\begin{array}{l}\text { Includes any statements that describe the high proportion of jobs } \\
\text { for youth that are agricultural in small towns; the difficulty of } \\
\text { finding non-agricultural jobs in very rural areas; the perceived } \\
\text { notion that if legal youth don't do these jobs, illegal immigrants } \\
\text { will have to be hired. Any comment that discussed "corn } \\
\text { detasseling" was also coded to this theme due to the strong linkage } \\
\text { in comments between that specific job and the idea that it was the } \\
\text { only job available to youth in that area. }\end{array}$ \\
\hline Danger of Other Activities & $\begin{array}{l}\text { Includes any reference to other jobs, sports, forms of entertainment, } \\
\text { or everyday activities being just as dangerous for youth (in the } \\
\text { author's opinion) as working on a farm. }\end{array}$ \\
\hline
\end{tabular}



manual work as a form of exercise; the healthiness of farm workers due to less obesity and/or higher activity levels.

The last two codes fell outside of the three overall node categories of degree of support, stakeholder, and theme. These last two codes were yes/no codes and related to the age of the author of the comment and the originality of the comment. Comments were tagged with a yes in the "author is a child" category if the comment's author referred to themselves as a current "farmkid," a current elementary/middle/high school student, under the age of 18, a current youth member of 4-H (under age 18), or any other close variation of the above list that unequivocally identified the author as a child under age 18 . Comments were tagged with a yes in the "form letter" category if the comment was comprised of the same text and format of at least one other letter within the sample. If a comment's author based his/her letter off of a form letter but made large and significantly notable changes to his/her comment rendering the comment unique, that comment was not be counted as a form letter. Noticeable changes to the form letter include adding additional paragraphs, making significantly large alterations/deletions, and/or attaching additional unique documents to the comment.

\section{Limitations}

There are several limitations of this research. First, the coding in NVivo was completed by one researcher. While this prevents coding variation between multiple researchers, it also subjects the coding classification to possible bias and error. Due to time constraints, a small and manageable sample size was selected. While the size and 
random selection of the 1000 comment sample ensures statistical validity at a 95 percent confidence level with a \pm 3 percentage point interval, nonetheless this means not every one of the 10,325 comments in the total population was analyzed. This creates additional potential for errors in the results.

This chapter presented the methodology utilized to attempt to understand the public participation in this NPRM and answer specific research questions related to the submitted comments. The chapter focused on the research design and methodology, the research questions, and the limitations. The next chapters present the results and discussion of the research. 


\section{CHAPTER 3: RESULTS-Who are the Stakeholders and What Did They Say?}

Adhering to the methodology described in Chapter 2, each of the 1000 comments of the sample were carefully coded and analyzed with NVivo content analysis software. The NVivo analysis allowed for a numerical tally of the different stakeholders commenting, degrees of support for the rule, and themes present in the comments within the sample. It also allowed for a numerical count of the comments in the sample that were form letters (see Appendices C-J) or were written by children. Furthermore, it made it possible to breakdown the link between stakeholder group and degree of support. Internode analysis created a better understanding of what each specific group of stakeholders had to say about the proposal and how that related to degrees of support. However, even though numerical tallies are used to display and discuss the results within this chapter, the focus of the analysis remains qualitative. Therefore, in describing the results, more attention is given to representative quotes taken from the sample comments than to quantitative results. Each excerpt or quote from a comment is identified by the last 4-5 digits (0001-10325) of its Federal Register ID number; personal names are omitted for privacy reasons, although named affiliations and organizations are not omitted. To present a full picture of the results, this chapter overviews the stakeholder group analysis, degree of support breakdown, theme identification results, and stakeholder/theme relationships.

Analysis of Stakeholder Groups

Using the coding descriptions for the stakeholders groups listed in Table 4, each comment was assigned a stakeholder code. The list of stakeholder groups was developed 
after an initial reading of the sample. The most common stakeholder group, with 443 comments, was "current farm resident." The next most common group was "unidentified" comments, with 265 comments. It is possible that the stakeholders within this category could have been members of the other stakeholder groups and just not identified themselves, either by simple omission or conscious choice. The next most common stakeholder groups, in order of largest number of comments to least number of comments, are former farm resident, non-farm resident with a direct farm employment connection, agricultural educator, other stakeholder, other organization, safety advocate, Farm Bureau organization, and lastly, government.

As described on the methodology section, each comment was carefully read for identifying descriptors in order to ascertain the stakeholder groups of the comments' authors. To better understand the makeup of the stakeholders, Table 7 includes both the number of comments that were attributed to each stakeholder group and an example from the sample of a stakeholder identifying themselves.

Table 7: Stakeholder Group Example Quotes

\begin{tabular}{|l|l|l|}
\hline $\begin{array}{l}\text { Name of Stakeholder } \\
\text { Group }\end{array}$ & $\begin{array}{l}\text { Number of } \\
\text { Comments }\end{array}$ & $\begin{array}{l}\text { Example from Comment of a Stakeholder } \\
\text { Identifying Themselves }\end{array}$ \\
\hline Current Farm Resident & 443 & $\begin{array}{l}\text { "I am a farmer in SW Michigan. I grew up on a } \\
\text { farm owned and operated by my parents..." -0098 }\end{array}$ \\
\hline Unidentified & 265 & $\begin{array}{l}\text { Comment lacked any substantial identification of } \\
\text { stakeholder affiliation. }\end{array}$ \\
\hline Former Farm Resident & 128 & $\begin{array}{l}\text { "As an American citizen who had the privilege of } \\
\text { growing up on a working farm and being involved } \\
\text { as a child in the agricultural portion of the 4-H } \\
\text { program, I understand the value of learning about }\end{array}$ \\
\hline
\end{tabular}




\begin{tabular}{|c|c|c|}
\hline & & $\begin{array}{l}\text { agriculture by actually performing the everyday } \\
\text { tasks of farming." }-9787\end{array}$ \\
\hline $\begin{array}{l}\text { Non-Farm Resident with } \\
\text { Direct Connection to Farm }\end{array}$ & 94 & $\begin{array}{l}\text { "Our two sons both worked for ranchers as } \\
\text { teenagers and it was a great experience[sic]." -1373 }\end{array}$ \\
\hline Agricultural Educator & 36 & $\begin{array}{l}\text { "As a high school agriculture teacher, I would like } \\
\text { to voice my displeasure at the proposed changes to } \\
\text { child labor laws." -0179 }\end{array}$ \\
\hline Other Stakeholder & 10 & $\begin{array}{l}\text { "Colonel US Army." -1244; "I am not a farmer, } \\
\text { nor do I have any business dealings with family- } \\
\text { operated farms. " -1805; "Republican Super Voter" } \\
-5486\end{array}$ \\
\hline $\begin{array}{l}\text { Other (Non-Governmental) } \\
\text { Organization }\end{array}$ & 10 & $\begin{array}{l}\text { "Yavapai Cattle Growers Association" -3174; "The } \\
\text { Crane Union High School class of 2015" -4735; } \\
\text { "The Center for Farmworker Families" -5179; etc. }\end{array}$ \\
\hline $\begin{array}{l}\text { (Children's) Safety } \\
\text { Advocate }\end{array}$ & 8 & $\begin{array}{l}\text { "D.Env, MPH, Director, New Jersey Safe Schools } \\
\text { Program, which ran a Task Force on Agricultural } \\
\text { Education in the State of New Jersey in spring-fall } \\
2009 . "-0124\end{array}$ \\
\hline Farm Bureau Organization & 5 & $\begin{array}{l}\text { "Illinois Farm Bureau (IFB) is a non-profit } \\
\text { membership organization with a total membership } \\
\text { of } 426,000 \text { and a voting membership of } 83,290 \\
\text { farmers and landowners." - } 10137\end{array}$ \\
\hline Government & 2 & $\begin{array}{l}\text { "The National Institute for Occupational Safety } \\
\text { and Health (NOISH) has reviewed the Department } \\
\text { of Labor Wage and Hour Division notice of } \\
\text { proposed rulemaking..." -4503 }\end{array}$ \\
\hline Total & 1000 & $\begin{array}{l}---- \\
\end{array}$ \\
\hline
\end{tabular}

While analyzing the comments for stakeholder affiliation, letters were also closely examined for discernible evidence that the author was a child under 18 and/or that the 
comment was a form letter. There were 113 form letters in the sample, and 100 letters discernibly written by a child in the sample. Of the form letters, there were seven different "against" from letters, which accounted for 107 of the total form letters. There was one "in favor" form letter, which accounted for the remaining six form letters. While it is likely that all the comments in the sample that were "form letters" were recognized, it is unlikely that all the comments written by youth under 18 were properly accredited. There is a strong possibility that not every youth author clearly identified themselves within the comment with an age. Therefore, the 100 comments identified as being authored by youth represents the minimum possible number in the sample.

\section{Degree of Support}

After identifying the stakeholder group, each comment was also analyzed to determine its degree of support. Comments were overwhelmingly against the proposal. These "against" comments ranged from profane and angry (WHD-2011-0001-2391) to disappointed (WHD-2011-0001-8662) or even understanding (WHD-2011-0001-6925). Although the range of negativity varied, 968 comments nonetheless clearly voiced a disfavorable opinion of the proposal. Only 32 comments within the sample were not outwardly against the DOL's proposal, with 19 in favor, eight mixed, and five neutral (see Table 8). Based on the extremely lopsided results of this analysis of the degree of support, it is possible to conclude that the vast majority of the comments received by the DOL were against the proposal. Indeed, this corresponds with information released from the DOL when the agency decided to withdraw the proposal (FR 77:103 31549). 
The results of the degree of support analysis coupled with the DOL's decision to withdraw the proposal indicates agency indicates responsiveness to public input. In notice and comment rulemaking, the interested public's submission of comments indicating support or lack of support for the proposed rule is the major method for democratic participation. In this rule, the DOL responded to the overwhelming lack of support by withdrawing the proposal. It appears that stakeholders who participated in the request for comment and voiced their concerns and apprehension towards the proposal had shaped their final decision to withdraw.

Table 8: Degree of Support Breakdown

\begin{tabular}{|l|l|}
\hline Degree of Support & Number of Comments \\
\hline Against & 968 \\
\hline In Favor & 19 \\
\hline Mixed & 8 \\
\hline Neutral & 5 \\
\hline Total & $\mathbf{1 0 0 0}$ \\
\hline
\end{tabular}

Since there are so many comments, 968, that voiced low degrees of support for the proposal, it is difficult to include a perfectly representational example of an "against" comment. A very brief example is comment 0466, which reads: "This proposal should not be considered. I strongly oppose it” (WHD-2011-0001-0466). Comment 0251, another shorter example, reads in its entirety: "This rule is a bad, bad idea. You are proposing a rule against instilling a work ethic in farm kids. Youth need to learn how to work, and a farm is a great place with a variety of jobs suitable for various ages, and kids 
learn to love it. Please do not do this to us" (WHD-2011-0001-0251). There are hundreds more examples, from a few words to multiple pages, all opposed to the proposal. These examples also include the seven form letters that were identified in the sample as against the proposal (see Appendices C-I for the seven disfavorable form letters).

There were just 19 comments in the sample in favor of the proposal. An example of a favorable degree of support is comment 1066. While very brief and short, it unambiguously declares its support for the proposal. The comment in its entirety reads: "I support the proposed child labor regulations. They should be issued without delay. Thank You" (WHD-2011-0001-1066). Others examples of favorable comments include a number of much longer submissions, including six identical copies of a favorable form letter (see Appendix $\mathbf{J}$ for a copy of the favorable form letter).

Eight comments coded as having mixed degrees of support. Several of these comments indicated support for some additional regulation, but not necessarily the entire proposal. Other comments coded as mixed had contradictory statements. An example of a mixed degree of support is comment 0847 . The unidentified stakeholder first indicates that she is in favor of the proposal because it would allow youth 14 and older to have a job. Since the proposal in fact restricts most youth ages 14 and 15 from agricultural jobs, it appears the comment's author may have been unclear as to the impacts of the proposal. Additional clarification in the comment would have likely resulted in it being coded as "in favor," but as it reads currently, it falls into the "mixed" category. The comment in its entirety reads: "I agree with this proposal very much. I believe that it is an excellent idea to allow youth from ages 14 and older to get jobs because it could help them develop 
good work ethics that they will need in the future when planning their careers. Also, it gives them more responsibility, training, and a smoother transition into adulthood while protecting their present day need for continued education and the dangers that could be present on the job site" (WHD-2011-0001-0847).

Lastly, five comments were coded as neutral. Although comment 2242 has a favorable view towards the proposal, it never takes a position for or against the proposal and just explains that the proposal made the individual more aware of the issue. It was therefore coded as neutral. It reads in its entirety: "I have a [sic] assignment requiring us to locate a proposed regulation that interests us. After reading the Child Labor Regulations, Orders and Statements of Interpretation; Child Labor Violations-Civil Money Penalties, I am now more aware of issues that have been stopped over the years. Thanks for caring for our youth, and for keeping them safe" (WHD-2011-0001-2242).

\section{Identification Top Concerns and Themes}

After identifying the stakeholder group and degree of support, each comment was coded for themes. As described in the previous chapter, the theme descriptions were identified after an initial reading of the comments in the sample and were not mutually exclusive. Table 9 breaks down the themes as coded across all 1000 comments.

Table 9: Theme Breakdown

\begin{tabular}{|l|l|}
\hline Theme & $\begin{array}{l}\text { Number of Comments (where that } \\
\text { theme was addressed at least once) }\end{array}$ \\
\hline On-the-job Training & 533 \\
\hline Work Ethic and Responsibility & 530 \\
\hline
\end{tabular}




\begin{tabular}{|l|l|}
\hline Rural Tradition and Lifestyle & 407 \\
\hline Governmental Lack of Understanding and Disconnect & 354 \\
\hline Parental Exemption, Definition & 325 \\
\hline Over-Regulation & 314 \\
\hline Importance of Child(ren)'s Safety & 274 \\
\hline 4-H and FFA Youth Programs & 273 \\
\hline America and Its Role & 208 \\
\hline Small Farmer/Small Business Impacts & 173 \\
\hline Bad Habits of Today's Youth & 162 \\
\hline Passion, Enjoyment & 151 \\
\hline Youth Finances & 139 \\
\hline Bad Economy & 94 \\
\hline (Only) Available Jobs in Rural Areas & 86 \\
\hline Danger of Other Activities & \\
\hline Rise in Obesity & \\
\hline
\end{tabular}

\section{On-the-Job Training}

On-the-job training represented the largest theme present in the comments. Over half of the comments, 533, addressed concern over a possible reduction in on-the-job training opportunities arising from the proposed new regulations. Although all of these 533 comments addressed on-the-job-training in some fashion, submitters took several different angles when addressing their concerns. Some focused on the need to train young people on the farm to ensure a future supply of farmers. Others were more concerned 
with on-the-job training in general to prepare teenagers for any potential future occupation. Still others looked at on-the-job training as an important tool to couple with in-the-classroom learning. Comment 3438 states: "the Department of Labor's proposed rules would cut out an import[a]nt learning tool called on-the-job training" (WHD-20110001-3438). Another comment, 3190, does not specifically use the phrase "on-the-job training," but it does reference the importance of on-the-farm experience to prepare for a future livestock career. "These young people also benefit from the experience of being mentored on the proper animal husbandry skills needed to be a successful livestock producer" (WHD-2011-0001-3190).

Comment 0038 says, "with good training from the farmer and watchfulness from him or his manager, children make good employees and the training they receive can be a life-changer for the better" (WHD-2011-0001-0038). Comment 0987 states: "if this rule goes into effect, the youngsters will no longer be allowed to assist with many normal, day to day activities. So will our farm give these youngsters the opportunity to be employed and learn about agriculture first hand? Probably not. They will be employed outside the agricultural industry and may be lost forever to agriculture" (WHD-2011-0001-0987). Comment 10137 asserts: "farmers believe that there is no better way to teach safety to the next generation of farmers than to begin working with children when they are most impressionable and reinforce those valuable lessons through supervised hands-on age appropriate activities and experiences" (WHD-2011-0001-10137).

This theme was primarily used as an overarching general argument against all aspects of the regulation. However, this theme also brought out some of the more 
contentious arguments regarding specific regulatory provisions of the proposal, including hazardous order \#1 regarding tractor usage and hazardous order \#4 regarding proximity to breeding livestock (as was addressed further in comment 3190). The word "tractor" is found within the sample 103 times in 79 different comments, suggesting it is considered by those within the sample to be an important aspect of on-the-job training. The agricultural educator stakeholder group also used this theme to address issues regarding the student learner exemption.

Work Ethic and Responsibility

Work ethic and responsibility was the next most common theme addressed. There were 530 comments with this theme. Similar to the on-the-job training code, this theme was raised primarily as a generalized concern against the entire proposal. Comments with this theme voiced concern as to whether the proposed regulatory restrictions would prevent children from working on farms in general and therefore inhibit children from learning good work ethics and character, attributes the commenters perceived to be linked to youth farm work. Another variation on this theme included commenters discussing their own work ethic, how it had been formed in the farm, and how it had impacted their own success. For example, this previous farm resident wrote: “what this 'job' [on my parents' farm] was doing to me was building character, building a strong work ethic. It taught me how to be responsible" (WHD-2011-0001-7682). Another approach used in discussing work ethic and responsibility discussed anecdotal evidence that "farmkids" are sought-after employees due to their hardworking nature. Comment 1920 takes this approach: "the best working group of people in this country are 
farm related folks. It was this way during WW 2 and it is the same today. Millitary [sic] leaders always wanted to get their hands on young farm men because they were responsible, hard working, and could fix anything” (WHD-2011-0001-1920).

Comment 0127 claims: "if it wasn't for farmers a lot of people would not know how to work. A young person wants to work on a farm to learn basic knowledge of how to work. They learn what responsibility is and how to take care of livestock from the ground up" (WHD-2011-0001-0127). Commenter 0140 states farm labor has had a positive impact on their employability, stating: "I am proud to be raised as a farmer's daughter, I put it on my resume and everyone of my past employees have looked at that and have hired me because of my work ethic that I received when I was younger" (WHD2011-0001-0140). Comment 0918 states with brevity: "this [farmwork] builds character and instills a great work ethic" (WHD-2011-0001-0918).

\section{$\underline{\text { Rural Tradition and Lifestyle }}$}

Four-hundred and seven comments addressed the rural tradition and lifestyle theme. This theme is mentioned in the April 26, 2012 DOL withdrawal of the proposal as being a factor in the DOL's decision to abandon the proposed changes (Lamont, 2012). Any comment addressing ideas of the regulation inhibiting the tradition, lifestyle, way of life, culture, or multi-generational customs of rural and farming areas was coded to this theme. Furthermore, this theme had a strong tie to the word "family." Examples include: "as a small livestock farmer living on a farm that has been in our family since 1852, I can tell you that farming is not an occupation. It is a calling. My parents passed on this calling to me when I was very young. One must truly love the farming lifestyle in order 
to answer this calling” (WHD-2011-0001-6856); “... a travesty to the way of life of rural America if allowed to pass" (WHD-2011-0001-2301); “...the department of labor wants to break the tradition of the family farm" (WHD-2011-0001-1625); and "...it is their right as country kids and it would be a tragedy to make them unwelcome in a cowboy tradition that stretches back generation after generation" (WHD-2011-0001-0102). Comment 0098 states: "if these proposed rules are implemented, it will deny the next generation of our family, including my grandson, the opportunity to have the same experiences that are vital to bringing the next generation into our family farm. These rules would destroy the generational family structure commonly found on farms" (WHD2011-0001-0098). Comment 1886 claims: “working side by side with 3 generations of my family provided a closeness that people outside of the farming community can rarely begin to fathom" (WHD-2011-0001-1886).

In direct contrast to the examples above and the over 500 other comments that address this theme of rural tradition and discussed the potential impact the proposed rule could have on the way they had chosen to raise their family, the DOL assured in the NPRM that this rule would not impact the well-being of families. The official language used in the NPRM is as follows: "the undersigned hereby certify that this proposed rule will not adversely affect the well-being of families, as discussed under section 654 of the Treasury and General Government Appropriations Act, 1999” (FR 76 No 171, Page 54874). The difference in interpretation of what would and would not impact rural farm families is expressed in this theme as well as several other themes, including the government disconnect theme, which is discussed below. 


\section{Governmental Lack of Understanding and Disconnect}

A little over one-third of the comments in the sample addressed the idea that the NPRM showed a governmental lack of understanding and/or disconnect. For example, comment 6856 questioned the DOL's firsthand familiarity with farming and wrote: "it is obvious that the Dept. of Labor is far removed from agriculture. In fact, if anyone in this group had firsthand knowledge of farm life it would never have been written as it is" (WHD-2011-0001-6856). Comment 5708 echoes this concern: “it seems Washington is continually assuming that they know best about everything for everyone and enact rules without reason..." the submitter later ponders, “...have any of the rule makers even lived in a rural community?" (WHD-2011-0001-5708). Comment 0377 writes: "I believe that you people have totally lost all contact with agricultural people" (WHD-2011-00010377).

This theme also included comments that addressed their frustration in more succinct ways. These descriptors all were used in regards to the proposal: "ridiculous" 2461; “asinine” -3192; “foolish"-1565; "STUPID”-5597; “preposterous"-4061; and "utterly misguided and frustrating" -3427.

\section{$\underline{\text { Parental Exemption, Definition }}$}

Roughly one in three comments discussed the parental exemption theme. This theme is unique in that it directly correlates with one of the specific provisions of the proposal, as opposed to other themes that address more general overall concerns. Comment 3174 states: “in particular, we oppose the proposed regulation's restrictions of the 'parental exemption' that has been a part of the Fair Labor Standards Act for decades. 
We believe that parental oversight is the key to safety on farms. The proposed regulations limit of the parental exemption by application of standards focusing on transfers of parental duties, or lack thereof, and location of work are arbitrary and inconsistent with the statute. We encourage the DOL to rewrite the provisions with a focus on child supervision by a competent adult and sensitivity to today's modern agricultural business structures and activities" (WHD-2011-0001-3174). Comments that did not mention the term parental exemption but voiced concern about the ability of grandparents, aunts, or uncles to still supervise children under the proposed regulation were also coded to this theme. Comment 0137 is an example of this: "if a family parents, grandparents, aunt, uncle or even family friend has a kid that wants to learn and help out, they should be allowed" ( WHD-2011-0001-0137). Comment 0357 also addressed this extended family sub-theme: "I strongly oppose changing child labor regulations, particularly those denying the right of relatives other than parents to supervise and employ youth in agriculture. Grandparents, uncles and aunts, older siblings, etc. are responsible, caring, safe guardians of young farm family members" (WHD-2011-0001-0357). Comment 0460 discusses extended family, too: "often family farms are run by extended families and the farm may not pass to a child of the owner. To not allow nieces, nephews, step-children, grandchildren or cousins the opportunities to work on the farm alongside their elders does a huge disservice to the kids who may someday be farmers themselves" (WHD-20110001-0460).

Furthermore, a comment also fell under the parental exemption theme if it addressed the definition of farm, for example tax classifications such as a partnership, 
limited liability corporation (LLC), or corporation (Inc.). Multiple examples of the farm definition approach can be seen in both original comments and form letter comments (see Appendices C-F, H). It appears these comments may have been a response to a specific sentence in the NRPM regarding the differences of parental sole ownership versus parental non-sole ownership and the treatment of exempt children. The DOL states on page 54,841 of the NPRM, "where the ownership or operation of the farm is vested in persons other than the parent, such as a business entity, corporation or partnership (unless wholly owned by the parent(s)), the child worker is responsible to persons other than, or in addition to, his or her parent, and his or her duties would be regulated by the corporation or partnership, which might not always have the child's best interests at heart" (FR 76 No 171, Page 54841).

This particular sentence of the fifty-three page proposal, a very small amount of text in comparison to the entire NPRM, garnered a significant amount of both direct and indirect response. For example, this comment from a state Farm Bureau organization addresses the sentence directly declaring: "in that statement, DOL suggests that rural America - because of the way farms are currently structured for tax, liability and inheritance purposes - is either incapable or unwilling to look out for its own. We could easily interpret that statement to say that without federal protection aunts and uncles and grandparents would be prone to exploit their young relatives for their labor and likely to put children in dangerous situations. Nothing could be further from the truth. Reading through the Federal Register, it is clear that particular interpretation represents a major source of the anger and disbelief reflected in literally hundreds of public comments 
submitted on the proposed rule" (WHD-2011-0001-10137). Comment 0987, written by a current farm resident, addresses how his farm could be treated differently due to its legal structure: "our farm is incorporated and this rule will negatively impact the learning process that has taken place on our farm for generations... who is more concerned about the youngsters safety than parents and grandparents? No one." (WHD-2011-0001-0987). Comment 1087 states: "I express reservation at passing proposed rule RIN 1235-AA06 as it is written. I have lived, worked and was an educator in the dairy business all my life. There are many family dairies which have organized for business purposes into a partnership or corporation. This does not necessarily describe size" (WHD-2011-00011087).

\section{Over-Regulation}

Three-hundred and fourteen comments considered the regulation to be a form of over-regulation. This theme was used as part of the generalized argument against the proposal. Comment 7716 declares: "stop overregulating us. These labor laws have gone too far. What children should be allowed to do on farms is between parents, children, and employers. The federal government has no right to get involved...Stop lying to the American people and burying us in paperwork." (WHD-2011-0001-7716). Comment 0475 states: "I can run MY OWN BUSINESS just FINE without further government intrusion" (WHD-2011-0001-0475). ) Comment 0630 asserts: "America is already doing what we can to safeguard children and adults. The proposed child labor regulations have gone overboard" (WHD-2011)-0001-0630). Comment 1335 declares: "let families determine how to run their farms based on the many years of their existence [sic]. Further 
regulation is not needed nor is it desired" (WHD-2011-0001-1335). Comment 9934 argues stakeholders already desire children's safety, and therefore, regulation is an unneeded burden: "the proposed rules step over the bounds of practicality and exhibit a heavy-handed approach to attempt to accomplish what we as parents, employers, and educators desire for our children already" (WHD-2011-0001-9934). Comment 9947 claims the unique, very broad nature of agriculture make additional regulation likely to be ineffective: "the number of distinct tasks and undertakings spanning the agricultural industry is simply too great for the Department of Labor to regulate effectively" (WHD2011-0001-9947).

\section{Importance of Child(ren)'s Safety}

The importance of children's safety theme is present in comments written in favor of the proposal (15/19 comments), comments written against the proposal (253/968), comments with mixed support (5/8 comments), and comments with neutral support (1/5 comments). This makes this node rather unique, being the only theme identified in the sample that appears in all four different degrees of support. It seems that regardless of the method in which stakeholders believed children's safety should be achieved - either with or without new regulations - 274 came together to agree in the importance of children's safety. Comment 3413, a written by current farm resident who was against the proposal, says: "Nothing is more important than the safety of my family and children" (WHD2011-0001-3413). Comment 1487, a form letter submitted by a safety expert who was in favor of the proposal, states: "it is vitally important that children of all ages, especially those under age 16, are protected from hazardous conditions at work" (WHD-2011-0001- 
1487). Comment 0104 states: "we care deeply about their safety and well being and are well qualified to make shure [sic] they learn and work safely" (WHD-2011-0001-0104). Commenter 0482, a farmer and grandmother, writes about her grandson working safely alongside older family members: "his grandfather and great grandfather take every opportunity to teach him the operation, including taking every precaution for safety" (WHD-2011-0001-0482).

Many commenters that had low degrees of support utilized this theme to segue into their lack of support for the DOL's proposal. For example comment 2560 states: "I do agree we need to protect our children working on the farm. No one values the safety of my family and others who work on my farm more than me. But we need to give them an opportunity to learn important skills, work ethic, and ways to stay safe by getting valuable hands-on experience on the farm" (WHD-2011-0001-2560). Comment 6720 declares: "you are assuming we are unable to teach them the safest way to work on the ranch or watch for their safety. Yet if we abide by the rule, they will be forced to spend their time at daycare or even worse, in the house playing games as opposed to learning the valuable lessons of everyday challenges and the logical resolutions of them" (WHD2011-0001-6720). Comment 8740 states: “I am all about [children's] safety, but this is not the way" (WHD-2011-0001-8740).

\section{$\underline{4-\mathrm{H} \text { and FFA Youth Programs }}$}

4-H and/or FFA youth programs were mentioned at least once in 273 of the comments. This theme was also one of the few themes present in comments that had favorable degrees of support for the proposal, the others being the "Importance of 
Child(ren)'s Safety" discussed above and "America and Its Role" discussed below. While the "in favor" form letter ( 4 of these were found within the sample) states the proposal would not hinder participation in agriculture due to the possibility of youth still being involved in the 4-H program, 269 other comments that addressed this theme were concerned that the proposal would do the opposite, hindering youth opportunities to be involved in both the 4-H and FFA organizations. This idea was particularly evident in the letters submitted by agricultural educators, including the agricultural educator form letter (see Appendix G). Examples listing concern about the future viability of agriculturallyrelated youth programs include comments 0640 and 3134: "programs like FFA and 4-H would also have problems with the proposed regulations. Many children would be denied excellent opportunities" (WHD-2011-0001-0640) and "your proposed regulations will have a severe dampening effect on organizations such as 4H and FFA" (WHD-20110001-3134). Comment 0673 questions: "how is this going to affect the $4 \mathrm{H}$ program? Most 4-H kids are under 16" (WHD-2011-0001-0673). Comment 2003 states: "if these regulations were around when I was 16, I would not have been able to show livestock for 4-H at the county fair, participate in an SAE or been able to receive my American FFA degree" (WHD-2011-0001-2003).

\section{America and Its Role}

Two-hundred and five comments written against the proposal contained reference to America and/or its role in feeding the world. The America theme was also present in two comments with mixed support and one comment with favorable support.

Overwhelmingly, however, this comment was utilized by those against the proposal to 
evoke a sense of patriotism towards agriculture and argue that the proposed regulations would diminish America, our great American heritage, and/or America's ability to produce food for the nation and world. Comment 6888 encompasses nearly all of those sub-themes, imploring: "[farmers] are the very people who raised the nation which is now home to so many people. Thanksgiving just passed and does anyone remember what happened on that day? The pilgrims were thankful for everything they had by having a feast of food they grew, not of what they imported from China. If more of these laws that prevent farmers from their jobs and living their lives, then everything will be imported, and who wants that? No one does. There's a saying, 'no farms, no food' and I tend to think about this motto a lot. Farming is one of the most important industries to this country, if not the most important. Everyone needs to eat, don't they?" (WHD-20110001-6888). Comment 0287 states: "the farmers of this country are the back bone for producers of food for the people" (WHD-2011-0001-0287). Comment 5277 warns: "if this bill [sic] is passed, the entire future of these united states will be doomed!!!!" (WHD2011-0001-5277). The idea of our founding fathers being farmers was also common; one comment calls them out by name, claiming: "George Washington and John Adams are rolling in their graves right now. Their families all worked together on their farms to support themselves while their father figures built this country for us to have all that we have" (WHD-2011-0001-5280).

\section{$\underline{\text { Small Farmer/Small Business Impacts }}$}

In 173 comments against the proposal, comment submitters argued that the proposed regulations would unduly impact small farmers and business owners as 
compared to larger (corporate) producers. In this theme, comments had to differentiate between small and large producers. In this analysis, corporate farms (which are differentiated from incorporated or limited liability corporation (llc) farms) were assumed to be an antonym to "small" farms. Notice that the examples below have a size or corporate farm component to their complaints. Comment 5671 begins by referencing family farms in general, but then uses a comparison of corporate versus small farms: "family farms cannot endure anymore government intrusion. Only corporate farms will be able to farm with all the hoops small farms are being made to jump through...Stop killing the family farm" (WHD-2011-5671). Similarly, another comment addresses the corporate farm idea: "this rule would only aid the corporate food producers who, by the way, are more dangerous to the public health than the local farm. This rule would further bind the local farmer and at the same time be an unnecessary boon to the corporate food industry" (WHD-2011-0001-7606). Comment 0700 states: "The small farmer is now gone due to government programs enabling bigger business to enter the agriculture community, don't let a program that you are proposing eliminate our younger generation from pursuing their dreams of working side by side with their parents on the farm" (WHD-2011-0001-0700).

\section{Bad Habits of Today's Youth}

The bad habits of youth today theme arose from negative references towards current youth activities such as playing video games, watching television, sitting on the couch inside and/or surfing the internet/computer. These activities were also sometimes associated within comments that addressed illegal activities for youth such as drinking 
alcohol, committing crimes, or using drugs. The general argument in 162 comments pertained to these bad habits being less present in youth who were busy working or growing up on a farm. For example, "I would rather see a child develop good work ethics by working any day over bad ones that they learn by sitting around watching TV and playing video games" (WHD-2011-0001-7836). This comment, written by a youth, claims that without farm work: "I don't have to do anything, but sit here and watch tv and play games on my computer" (WHD-2011-0001-0140). This comment, written by an adult, echoes the same phrase, saying: "youth will only sit and play video games if unable to work" (WHD-2011-0001-0286). Comment 9941 states: "when they are working and making something of them self they are less likely going out and causing problems" (WHD-2011-0001-9941).

$\underline{\text { Passion, Enjoyment }}$

A wide variety of stakeholders, including current farm residents, former farm residents, non-farm residents, and unidentified stakeholders noted youth's love, passion, and enjoyment of agricultural work. One-hundred-fifty-one letters addressed this theme, including a number of comments written by children themselves. "Some [farm and ranch kids] have a burning passion and love for what they do, and it will only be smothered if these laws are passed" (WHD-2011-0001-3361). Commenter 0287 states: "I grew up on a farm and worked hard and I enjoyed it" (WHD-2011-0001-0287). Commenter 2916 writes of a similar experience growing up: "I am 52 and fell in love with farming at the age of 13 while helping my uncle raise hogs and cattle, make hay, and drive tractors" (WHD-2011-0001-2916). Commenter 1025 writes about her son: "my son, 14 years old, 
currently milks cows and does light farm work for a neighboring farmer. HE LOVES IT!" (WHD-2011-0001-1025). Commenter 1555 wrote about how her past positive youth involvement with agriculture informed her decision to become a high school agriculture teacher: "I found a passion while in high school and that passion was agricultural education" (WHD-2011-0001-1555). This comment, written by a youth, tells of how working on the farm with her siblings is an enjoyable and rewarding experience: "My brothers and I [are] completely willing to help in any way shape or form with a smile on our faces and have since we were little, like most of the farm kids in our area. I started taking steers to the fair when I was eight years old, and it was the most rewarding experience I could've ever had" (WHD-2011-0001-2461).

\section{$\underline{\text { Youth Finances }}$}

The youth finances theme, present in 139 comments, closely relates to the bad economy theme. However, the youth finances theme relates to a youth's personal finances whereas the bad economy theme referred more to national finances. Commenters gave anecdotal evidence of their own ability or their children's ability to make significant purchases like cars or computers, save for college, have small cash available for incidentals, or even help contribute to making ends meet for their family. This former youth farm employee writes: "my jobs on the ranch allowed me to earn money for college and even buy my first car" (WHD-2011-0001 -2553). This agricultural employer says: "many children like the opportunity to earn a little money by working on a farm" (WHD-2011-0001-3358). This youth farmworker wrote about the income she earned and saved from her annual summer job on a strawberry farm: "over the four years 
that I have worked there, I have made around $\$ 3,000$ and have learned the importance of saving” (WHD-2011-0001-0864). This youth worker was also concerned about how the proposed regulation could affect his personal finances: "WOW!!!!! WHO do you think you are trying to take my job? Kids out here in the COUNTRY work for a living. You may think you are protecting when you are actually hurting kids who are trying to make money for college" (WHD-2011-0001-2818).

\section{$\underline{\text { Bad Economy }}$}

The Great Recession of December 2007 to June 2009 and the state of the American economy was an important broader topic that found its way into ninety-four of the comments within the sample. Although not mentioned as often as many of the other themes, commenters who addressed the economy within their comment were quite passionate about the topic. An excerpt from comment 4772 reads: "just because you have good intentions does not mean you know what you are doing. And you do not know what you are doing. You have made enough messes with the likes of SS, medicare, the debt crisis, the economy, unemployment, lack of border security... need I go on" (WHD-20110001-4772). Comment 1006 states: "the government needs to work on getting people back to work and taking care of the national debt. Let the parents decide what is best for their children" (WHD-2011-0001-1006). Commenter 5681 asks: "in a time with high unemployment and the beginning of inflation, [w] hy would this be on the table?" (WHD2011-0001-5681). Commenter 6826 wonders: "kids can't find jobs in today's economy and now you want to take away farm jobs?" (WHD-2011-0001-6826). 


\section{(Only) Available Jobs in Rural Areas}

Although the DOL asserted "that implementation of the proposed rule would not reduce the overall number of safe, positive, and legal employment opportunities available to young workers" (FR 76 No 171, Page 54841), numerous comments disagreed. Eightysix comment submitters perceived that agricultural jobs are amongst the only jobs available to youth in rural areas. An interesting sub-set of comments within this theme focused on one specific job: detasseling, which is the act of removing the male flowers on corn plants to prevent cross pollination during corn breeding. In the comments, detasseling is identified as a youth dominated summer job. This example, 5712, from Nebraska addresses both detasseling and the lack of other jobs for youth: "youth in Nebraska also have the opportunity to join detasseling crews during the summer, and many of these kids do this because it is about the only job available to someone who does not have their driver's license" (WHD-2011-0001-5712).

Other comments focused on jobs other than just detasseling. This comment stresses the overall reduction of jobs for rural teens, claiming: "passing this law [sic] would eliminate any source of income for teens in areas where there is nowhere else to work" (WHD-2011-0001-2135). Comment 0290 also writes about the shortage of rural jobs: "denying ambitious teenagers the right to work, especially [sic] in rural areas where jobs for teenagers are scarce to begin with, does nothing but hurt that teenager" (WHD2011-0001-0290). Comment 5224, a youth submission, states: "this job was the only job I could get” (WHD-2011-0001-5224). 


\section{Danger of Other Activities}

Eighty-one commenters perceived children working on farms to be equally or less dangerous than other activities. Although the following example is a long excerpt, it excellently summarizes the position taken in many of the other 80 comments that addressed this theme: "while we understand the dangers involved in agriculture, we also understand that there are more dangerous activities for our children such as riding in a car. There were more than 5.5 million car accidents in 2009. Of those accidents an average of four children under the age of 14 were killed every day and nearly 500 were injured. We also understand letting our children be involved in sporting activities also involves a huge risk of injury. According to a Loyola University Study based on 2005 data from the U.S. Consumer Product Safety Commission more than half a million kids went to the ER in just one year with injuries sustained playing basketball. About 20 percent of children and adolescents participating in sports activities are injured each year, and one in four injuries is considered serious. But, with the right training, supervision, and equipment, most sports can be considered safe for children. Parents of kids in extreme sports point out that danger is all around us, and you can't raise your child in a bubble. I concur” (WHD-2011-0001-3533).

\section{$\underline{\text { Rise in Obesity }}$}

Although mentioned in just 21 out of 1000 comments, the rise in obesity theme is nonetheless notable. While seemingly unrelated to the proposal, 21 commenters found that the potential restrictions on agricultural jobs, a form of often outdoor manual labor, could have implications on youth fitness and obesity. Furthermore, comments identified 
that the same administration that advocated for increased focus on children's obesity issues also had suggested this proposal. This employer of youth and current farm resident writes: "[farm work] teaches them the value of working and it gives them good exercise. Is not the government concerned about childhood obesity? I feel there is nothing wrong with having a young teenager learn the value of work in return for a fair wage and keeping fit at the same time" (WHD-2011-0001-6802). This individual writes: "too many children are now suffering with obesity because they do not do any manual labor" (WHD-2011-0001-1631). Comment 0033 states: "this country is concerned about the diets of our obese kids, but did it ever occur to the powers that be, that it is hard to keep someone fit who spends more time with their electronic gadgets than they do working at something constructive for their family or society" (WHD-2011-0001-0033).

\section{Link Between Support and Stakeholder Group/Theme}

Due to the strong participation of stakeholders with current and/or former farm connections and the overwhelming number of negative of the comments (968) towards the proposal, it is clear that the stakeholders connected to farms and ranches had a low degree of support for the proposal. However due to the much smaller numbers of nonfarm identified stakeholders and the small number of comments in favor of the proposal (19), concluding from this analysis that certain group(s) of stakeholders were associated with favorable support for the proposal is difficult. For example, although a majority of safety experts in the sample (6/8) were against the proposal, that number (6) of commenters comprises just .006 percent of the sample and is statistically insignificant 
after adding a \pm 3 percentage point confidence interval. For a numerical breakdown of the linkage between stakeholders and degree of support within the sample, see Table 10.

Table 10: Stakeholder Groups and Degree of Support

\begin{tabular}{|c|c|c|c|c|c|}
\hline Group & & & Suppor & & Total \\
\hline Stakeholder & Against & In favor & Mixed & Neutral & ------ \\
\hline $\begin{array}{l}\text { Current Farm } \\
\text { Resident }\end{array}$ & 441 & 0 & 2 & 0 & 443 \\
\hline Unidentified & 248 & 9 & 4 & 4 & 265 \\
\hline $\begin{array}{l}\text { Former Farm } \\
\text { Resident }\end{array}$ & 125 & 0 & 2 & 1 & 128 \\
\hline $\begin{array}{l}\text { Non-Farm w/ } \\
\text { Direct Connection } \\
\text { to Farm }\end{array}$ & 94 & 0 & 0 & 0 & 94 \\
\hline Ag Educator & 36 & 0 & 0 & 0 & 36 \\
\hline Other Stakeholder & 9 & 1 & 0 & 0 & 10 \\
\hline $\begin{array}{l}\text { Other (Non- } \\
\text { Governmental) } \\
\text { Organization }\end{array}$ & 8 & 2 & 0 & 0 & 10 \\
\hline $\begin{array}{l}\text { (Children's) } \\
\text { Safety Advocate }\end{array}$ & 2 & 6 & 0 & 0 & 8 \\
\hline Farm Bureau & 5 & 0 & 0 & 0 & 5 \\
\hline Government & 1 & 1 & 0 & 0 & 2 \\
\hline Total & 968 & 19 & 8 & 5 & 1000 \\
\hline
\end{tabular}

In regards to the connection between degree of support, stakeholder group, and concerns/themes, there are some linkages to be noted. Due to the high proportion of 
comments against the proposal, coded themes are primarily associated with "against" submissions by stakeholders with a connection to a farm. Only three themes were identified in favorable support submissions: importance of child(ren's) safety, 4- $\mathrm{H}$ and FFA, and America and Its Role. The importance of child(ren's) safety theme was identified in all of the letters by children's safety advocates.

In addition to the results obtained in this analysis, the various DOL publications released on the proposal help illuminate the linkages the DOL made between participating stakeholder groups and support for the proposal during their own analysis of the comments. In their news releases and publications, the DOL notes the concern and lack of support for the proposal from farm-related stakeholders and others. Another interesting point made in the DOL publications is that not all stakeholder share equal weight in the comment review. Although several stakeholder groups are mentioned in contributing to the DOL's decision to withdraw the proposal, only one group is identified by number: Congress. The DOL indicated a strong participation from Congressional members, "including 153 Members of the House of Representatives [and] 42 United States Senators" (FR 77:103, page 31549). It appears, understandably, this stakeholder group carried a greater weight than other participants. 


\section{CHAPTER 4: DISCUSSION OF RESULTS}

The previous chapters outline the regulatory process, the history of agricultural safety legislation, the DOL's 2011 proposed changes to children's agricultural safety, the methodology used to analyze the response to the DOL's proposal, and finally the results of the content analysis of a 1000 comment sample. The results, which show strong participation from farm-related stakeholders, an overwhelmingly low degree of support for the proposal, and the most prevalent theme to be concern over on the on-the-job training opportunities, correspond with the DOL's published reaction and final decision on the regulation.

In the Federal Register, the DOL's notice of withdrawal states: “the Department received over 10,000 comments on the proposed rule. Many of the comments were from parents who own or operate farms who believed that the Department's proposal would limit their ability to employ their own children on their farm and to provide their children with hands-on experiences in agricultural occupations. Other commenters, including 153 Members of the House of Representatives, 42 United States Senators, and a number of agricultural education instructors, emphasized the importance of preparing the next generation of farmers and ranchers. These individuals also stated that the Department's proposal to increase the rigor of the current student learner exemptions that allow 14- and 15-year-olds to be employed in certain occupations that the Secretary has declared are particularly hazardous for children under the age of 16 , would unduly limit the work young children could be employed to perform on a farm and thereby limit their opportunity to learn about farming through hands-on experience and discourage them 
from entering the field of farming" (FR 77:103, page 31549). The following discussion elaborates on the results of the previous chapter, interpreting the meaning of the results, suggesting the impact of public participation in this proposed rule, explaining methods to increase stakeholder involvement, and proposing possible next steps.

\section{Interpreting the Results of the Analysis}

The results indicate that the support for the proposal was low. Although 968 out of 1000 comments in the sample were against the proposal, it is important to note that these results cannot be assumed to match the opinion of the general public. The individuals and organizations that chose to submit comments self-selected themselves into the population. Therefore, both the 10,325 comments submitted and the 1000 comment sample analyzed in this thesis represent a biased segment of stakeholders. These comments are biased because they represent individuals and organizations with a high enough level of concern regarding the NPRM to expend the effort and time to submit a response to the Federal Register. This is evidenced by the relative homogeneity of stakeholder groups represented in the sample as compared to the distribution of these stakeholder groups within the general public. These stakeholders represented individuals and organizations with political awareness and access. For example, the results showed very little response from migrant workers, which indicates that some very important and highly affected stakeholders were not present in the discussion regarding this NPRM. While the results are not necessarily representative of the general public's support of the proposal, they do nonetheless provide insight into the degree of support and concerns of (some of the) major relevant stakeholders who are interested and affected enough to write 
a comment. The results also provide insight into issues of inclusion and exclusion of individuals in notice-and-comment rulemaking participation.

Stakeholder concerns, which were coded through identified themes, were primarily related to generalized arguments against the proposal, not specific concerns regarding individual provisions or hazardous orders in the regulation. Exceptions to this trend include the Parental Exemption and to a lesser extent the Student-Learner Exemption, a small sub-theme expressed in both the On-the-Job Training and 4-H and FFA themes. In contrast to the Parental Exemption theme that was discussed in 325 comments in the sample, a much smaller number of comments in the sample addressed specific proposed hazardous orders and/or the student-learner exemption. Analyzing specific hazardous orders was very rare in original comments. However, a 3 out of 8 (non-original) "against" form letters did address problems with specific hazardous orders - either pointing out perceived burdensomeness or potential for unclearness in the future interpretation of specific provisions (see Appendices C, D and G for form letters that address specific provisions of the regulation and/or hazardous orders). Many original comments focused on a more anecdotal approach, invoking the images of a traditional rural lifestyle that could be jeopardized instead of addressing specific hazardous orders (see Figure 2). The anecdotal evidence approach was also utilized by many of the 100 comments submitted by youth. 
Figure 2: Example of "Against" Comment with Focus on Anecdotal Evidence

"I was raised on a ranch and grew up with a deep love of animals. When there was an orphaned calf

Bottom-Up Rulemaking and Next Steps

Government disconnect and lack of understanding was the fourth most common theme addressed in the sample. Although it is not the most common theme, it is particularly important to this discussion. The high prevalence of this theme shows the DOL lacked buy-in from comment submitters. Although the DOL's NPRM has a plethora of cited research and statistics, it shows little evidence of stakeholder involvement. This perceived, or possibly real, lack of stakeholder involvement, particularly from farm-related stakeholders and agricultural educators, helped to build distrust and disbelief between the major stakeholders and the DOL. A lack of buy-in can 
reduce satisfaction and success in rulemaking, leading to either a complete withdrawal of the rule as occurred in this case or a rule that is enacted but is not followed.

The (perceived) lack of stakeholder involvement and negative foundation of trust is evident in the comments that address the government disconnect theme. Farm residents questioned whether regulators had ever visited a farm or were familiar with rural life. This comment, from the Illinois Farm Bureau, addresses the lack of diversity in the sources and stakeholders used in developing the NPRM: "there are many troubling aspects of this proposed rule. One of them is the heavy reliance, bordering on blind acceptance of a report released last year by the group Human Rights Watch" (WHD2011-0001-10137).

Another aspect of the proposal that some stakeholders interpreted as government disconnect was the timing of the comment period, September to November. These months correspond with the main harvest season across the United States. Some of the earliest comments addressed this overlook in timing, requesting that the comment period be extended past the original November 1, 2011 deadline. The DOL acquiesced to the requests, listing as reason for the extension requests "from members of Congress and various agricultural business organizations, including, but not limited to:

American Sheep Industry Association; National Cattlemen's Beef Association; National Pork Producers Council; National Turkey Federation; California Farm Bureau Federation; National Association of State Departments of Agriculture; National Association of Agricultural Employers; National FFA Organization; and the American Farm Bureau Federation" (FR 76: 210, page 67104). Future requests for stakeholder 
involvement from the DOL should be cognizant of the seasonal commitments of agriculture, which may inhibit some groups of stakeholders from participating fully during certain times of the year.

Utilizing a bottom-up approach to rulemaking could help foster greater understanding between the DOL and concerned stakeholders and more satisfactory regulations. Increased stakeholder involvement may have led to higher degree of support for a children's agricultural safety proposal. Other bottom-up approaches to rulemaking have indeed resulted in better outcomes. For example, Laura Langbein and Cornelius Kerwin compared eight negotiated rulemakings to six non-negotiated rulemakings and found a greater level of satisfaction with the final rule when it was negotiated (Langbein, 2000). A National Academies of Sciences report analyzing numerous studies of bottomup approaches to policymaking concluded that effective public participation can "improve[e] the quality and legitimacy of a decision and buil[d] the capacity of all involved to engage in the policy process" (National Research Council, 2008). At the very minimum, utilizing a more bottom-up approach in the rulemaking analyzed in this thesis may have alerted the DOL ahead of time of the need for a longer comment period due to harvest time.

Negotiated rulemaking is just one bottom-up approach, with other options including but not limited to: focus groups, citizen advisory panels, public opinion surveys, and consensus conferences. Gene Rowe and Lynn Frewer (2000) found in their research of public participation methods that selecting a bottom-up approach in the development of a policy should be done with the specific context of the policy and 
desired outcome of the participation process in mind. They write, "given that the quality of the output of any participation exercise is difficult to determine, the authors suggest the need to consider which aspects of the process are desirable and then to measure the presence or quality of these process aspects" (Rowe, 2000). Bearing this in mind, the DOL can learn from the lack of stakeholder support and ultimate failure of their 2011 proposal and establish goals for a more "desirable" public participation process in future children's agricultural safety policymaking. Arguably these goals should include increased trust from farm-related stakeholders and improved policy legitimacy. These goals could be achieved through a significant deliberative process with affected and interested stakeholders that begins at the initiation of the policy process - not after the creation of the proposal.

In the withdrawal of the proposal, the DOL indicated that a non-regulatory, educational policy approach would be its next step. The DOL also indicated that for the duration of the Obama Administration, no further regulatory changes in children's agricultural safety would be proposed (Lamont, 2012). Therefore, negotiated rulemaking is not an appropriate suggestion as regulation is not being considered at present.

However, the bottom-up concept of negotiated rulemaking could be applied to the DOL's educational policy approach. The success of the new educational approach, similar to a regulatory approach, hinges on stakeholder buy-in. Due to the education focus of the new proposed approach, stakeholder buy-in must occur particularly from the agricultural education community. It is unreasonable to expect success of an agricultural safety education program if the educators teaching the materials and the students being educated 
do not agree with the educational curriculum. Therefore, as an ideal next step to increase legitimacy and trust in the educational policy approach, the DOL could utilize focus groups early in the development process containing a mix of all stakeholder groups, but particularly emphasizing representation from agricultural educators, parents and youth. Additionally, since this analysis showed a lack of representation from both youth and adult migrant workers during the notice-and-comment period, it is important to ensure this stakeholder group is adequately represented in future stakeholder involvement. The successful NAGCAT program, the integration of agricultural safety curriculum into English-as-a-Second-Language classes, and the bottom-up concept used in negotiated rulemaking could be used as models for the DOL as they work to form of collaborative bottom-up educational program. This program should utilize the expertise of educator, parent, youth, migrant worker, and safety expert stakeholder groups.

Furthermore, in developing the format and facilitation directives of the focus groups, the DOL should draw upon the extensive field of risk perception. Addressing children's agricultural safety must include addressing the different ways the various stakeholder groups characterize the risk to youth participating in agricultural employment. Although risk was not a separate theme identified in the sample analysis, it was an underlying concept woven subtly through the comments: what stakeholders against the proposal saw as appropriate on-the-job training for youth (minimal, acceptable risk), stakeholders in favor of the proposal saw as inappropriate risk to youth (high, unacceptable risk). Furthermore, due to the lack representation of migrant worker stakeholders in the analyzed sample, it is unclear what this stakeholder group sees as 
acceptable risk to youth. According to the National Research Council's book, Understanding Risk: Informing Decisions in a Democratic Society, "a risk characterization must address what the interested and affected parties believe to be at risk in the particular situation, and it must incorporate their perspectives and specialized knowledge. It may need to consider alternative sets of assumptions that may lead to divergent estimates of risk to address social, economic, ecological and ethical consequences for human health and safety" $(1996,3)$. Therefore, it is important to incorporate a discussion of risk into the deliberative focus groups, potentially enabling affected stakeholder groups to understand the perspectives of other participating stakeholders that possess opposing views and differing knowledge.

\section{Conclusion}

Utilizing a qualitative content analysis approach shed light on the participatory response of concerned stakeholders to the DOL's 2011 proposed changes to children's agricultural safety regulation. An analysis of 1000 randomly selected comments submitted to the Federal Register in response to the proposal showed an overwhelmingly low degree of support for the proposal and a high proportion of participation from farmrelated stakeholders. It also revealed low participation from some important affected stakeholders, such as migrant farmworkers. A review of the NPRM reveals a lack of evidence of stakeholder involvement from farm-related stakeholders during the development phases of the regulation, which may have contributed to the ultimate failure of the proposal. Although the proposal was withdrawn, the higher fatality and injury rates for youth in the agricultural still remain high compared to other industries. In the notice 
of withdrawal, the DOL listed a non-regulatory, educational approach as its next step to addressing children's agricultural safety problems. A proposed educational approach to this policy problem may have greater success than the recent proposed regulation if a bottom-up approach with broad stakeholder involvement is utilized. One possible bottom-up approach is to consult interested and affected stakeholders through deliberative focus groups. To ensure buy-in and legitimacy, it is important to initiate focus group participation prior to the formation of the DOL's educational approach proposal. Additionally, inclusion of appropriate representation from agricultural educators, parents, migrant workers, and youth is necessary due to the important roles they play in defining what is appropriate risk for children and the ultimate success or failure of any educationally based approach to improving children's agricultural safety. 


\section{References}

Alexander, Elizabeth and Laura McGinnis. (2012, Feb 1) 'US Labor Department to repropose 'parental exemption' of child labor in agriculture rule." DOL.gov. www.dol.gov/opa/media/press/whd/WHD20120203.htm.

American Bar Association. (2001) Adjudication . http://www.americanbar.org/content/ dam/aba/migrated/sections/adminlaw/PublicPublicDoc/Adjudication.doc-26k.

Baker, Robin, James Meyer and Jeff Ponting. (2011) "Evaluating Teen Farmworker Education: An Evaluation of a High School ESL Health and Safety Curriculum." High Impact: A Project from the First 10 Years of NORA. NIOSH, 2011-113. http://www.cdc.gov/niosh/docs/2011-113/pdfs/2011-113.pdf.

Calcott, Paul. (2008) "Negotiation versus consultation in the development of a regulation.” 39:2 Environmental Resource Economics. http://www.springerlink. com/content/r701105514835320/.

Coglianese, Cary. (1997) “Assessing Consensus: The Promise and Performance of Negotiated Rulemaking." 46:6 The Duke Law Review.

Coglianese, Cary, Heather Kilmartin, and Evan Mendelson. (2009) “Transparency and Public Participation in the Federal Rulemaking Process: Recommendation for the New Administration." 77:4 The George Washington Law Review.

Department of Health and Human Services (DHHS). (March 2012) Are You a Teenworker: Updated. NIOSH, 2012-130. http://www.cdc.gov/niosh/docs/2012130/pdfs/2012-130.pdf. 
Federal Register, Child Labor Regulations, Orders and Statements of Interpretation; Child Labor Violations-Civil Money Penalties; Proposed Rule, 76: 171. (Washington DC: Sept. 2011).

Federal Register, Child Labor Regulations, Orders and Statements of Interpretation; Child Labor Violations - Civil Money Penalties; Notice of public hearing, 76: 192. (Washington DC: Oct 2011).

Federal Register, Child Labor Regulations, Orders and Statements of Interpretation; Child Labor Violations-Civil Money Penalties; Notice and Extension of comment period, 76: 210. (Washington DC: Oct 2011).

Federal Register, Child Labor Regulations, Orders and Statements of Interpretation; Child Labor Violations - Civil Money Penalties; Withdrawal of proposed rule, 77: 103. (Washington DC: May 2012).

Gadomski, Anne, et. al. (2006) "Efficacy of the North American Guideline's for Children's Agricultural Tasks in Reducing Childhood Agricultural Injuries." 96:4 American Journal of Public Health.

Harter, Philip (2001) “Assessing the Assessors: The Actual Performance of Negotiated Rulemaking," 9 New York University Environmental Law Journal, 32.

ICF Consulting (2003) “The Reg Map: Informal Rulemaking,"Reginfo.gov. U.S. General Services Administration's Regulatory Information Service Center. http://www.reginfo.gov/public/reginfo/Regmap/index.jsp. 
Lamont, Joshua and Elizabeth Alexander. (2012, April 26). "Labor Department statement on withdrawal of proposed rule dealing with children who work in agricultural vocations." DOL.gov. www.dol.gov/opa/media/press/whd/WHD20120826.htm.

Langbein, Laura and Cornelius M. Kerwin. (2000) "Regulatory Negotiation versus Conventional Rule Making: Claims, Counterclaims, and Empirical Evidence.” Journal of Public Administration Research and Theory. 10 (3): 599-632. Oxford. Levine, Marvin (2003) "Risks for Child Labor in Agriculture," Children for Hire: The Perils of Child Labor in the United States, Westport 105-06.

Lubbers, Jeffery S. (2006) A Guide to Federal Agency Rulemaking, Fourth Edition. American Bar Association.

Marienga, Barbara, et al. (2007, Feb.) "Changing the Child Labor Laws for Agriculture: Impact on Injury.” American Journal of Public Health.97: 2. 276-282.

McGinnis, Laura and Sonia Melendez. (2011, Aug 31) “US Labor Department proposes updates to child labor regulations." DOL.gov. www.dol.gov/opa/media/press/whd/ WHD20111250.htm.

Miller, Bev. (2011, Feb 8) “Getting a Random Sample.” University of Wisconsin-Eau Claire. https://www.uwec.edu/help/Excel07/randomdata.htm.

National Research Council. (2008) Public Participation in Environmental Assessment and Decision Making. Panel on Public Participation in Environmental Assessment and Decision Making, Thomas Dietz and Paul C. Stern, eds. Committee on the Human Dimensions of Global Change. Division of Behavioral and Social Sciences and Education. Washington DC: The National Academies Press. 
National Research Council. (1996) "SUMMARY." Understanding Risk: Informing

Decisions in a Democratic Society. Committee on Risk Characterization.

Washington, DC: The National Academies Press.

Obama, Barack. (2011, Jan 18) "Improving Regulation and Regulatory Review." Executive Order 13563. Federal Register 76:14. http://www.reginfo.gov/public/jsp/Utilities/EO_13563.pdf

O'Donoghue, Erik Robert Hoppe, David Banker, and Penni Korb. (2009, March) "Exploring Alternative Farm Definitions: Implications for Agricultural Statistics and Program Eligibility.” Economic Information Bulletin No. (EIB-49): 41.

Office of the Federal Register. (2011) A Guide to the Rulemaking Process. Office of the Federal Register. https://www.federalregister.gov/uploads/2011/01 /the_rulemaking_process.pdf.

Office of Information and Regulatory Affairs (2012). "FAQ." Reginfo.gov. http://www.reginfo.gov/public/jsp/Utilities/faq.jsp.

Regulations.gov. (2012) “About Us: Enhancements and Fixes.” United States eRulemaking Program. http://www.regulations.gov/\#!aboutEnhancements.

Rivara, Fred. (1985) "Fatal and non-fatal farm injuries to children and adolescents in the United States." Pediatrics 76:4.

Rossi, Jim. (1997), Participation Run Amok: The Costs of Mass Participation for Deliberative Agency Decision Making, 92 Northwestern University Law Review $173,224-25$. 
Rowe, Gene and Lynn J. Frewer. (2000) "Public Participation Methods: A Framework for Evaluation.” Science Technology Human Values Winter 2000 vol. 25 no. 13 29.

Shulman, S. W. (2009), “The Case Against Mass E-mails: Perverse Incentives and Low Quality Public Participation in U.S. Federal Rulemaking.” Policy \& Internet, 1: 23-53. doi: 10.2202/1944-2866.1010.

Windau, Janice, Eric Sygnatur, and Guy Toscano. (June 1999), "Profile of work injuries incurred by young workers.” Monthly Labor Review. Bureau of Labor Statistics. http://www.bls.gov/mlr/1999/06/art1full.pdf.

Vardeman, Steve. (2008, March 4), Creating a Simple Random Sample in Microsoft ${ }^{\circledR}$ Excel. http://www.public.iastate.edu/ vardeman/book_site/excel/random_ sample/random_sample.html. 


\section{Appendix A: Parental Exemption Excerpt from DOL Proposal}

"The same 1966 amendments to the FLSA that authorized the Secretary to issue the Ag H.O.s also clarified the parental exemption, addressed the minimum age standards for employment in agriculture, and brought many agricultural workers under the Act's minimum wage provisions for the first time. Under section 3(1) of the Act, children under the age of 16 who are employed by their parents or person(s) standing in place of their parents may be employed at any time and in any occupation other than manufacturing, mining, or an occupation found by the Secretary to be particularly hazardous for youth between the ages of 16 and 18. Section 13(c) of the Act expanded the parental exemption as it applies to agricultural employment in two ways. First, the parental exemption in 13(c)(1)(A) applies not only to youth who are employed by their parents or persons standing in place thereof on a farm that is owned by such individuals, but to youth who are employed by their parents or persons standing in place thereof on farms that are operated by, but not owned by, those individuals. Youth who are working pursuant to this 'operated by' exemption must be employed outside of school hours. Second, section 13(c)(2) permits youth who are employed by their parents or persons standing in place thereof on farms owned or operated by those individuals to work in occupations that have been deemed by the Secretary to be hazardous to the employment of children under the age of 16. This exemption is much broader than the parental exemption in nonagricultural employment where the restrictions regarding the employment of youth in the 17 nonagricultural hazardous occupations orders remain until the age of 18 .

The parental exemptions in the FLSA, which permit children to be employed by their parents in some otherwise prohibited occupations, were not predicated on the belief that the children of business owners and/or farmers were more physically or mentally advanced, more safety conscious, or in possession of more cautious work habits than their peers. Instead, these exemptions were granted in recognition of, and continue to rely upon, the concept that a parent's natural concern for his or her child's well-being will serve to protect the child. Congress, as evidenced by discussion on the floor of the House of Representatives (see Congressional Record, 75th Congress, page 1693, December 16, 1937) intended that the parental exemptions be applied quite narrowly, limiting their application to parents and those standing in place of a parent.

Accordingly, application of the parental exemption in agriculture has been for over forty years limited to the employment of children exclusively by their parent(s) on a farm owned or operated by the parent(s) or person(s) standing in their place. Any other applications would render the parental safeguard ineffective. Only the owner or operator of a farm is in a position to regulate the duties of his or her child and provide guidance. Where the ownership or operation of the farm is vested in persons other than the parent, such as a business entity, corporation or partnership (unless wholly owned by the 
parent(s)), the child worker is responsible to persons other than, or in addition to, his or her parent, and his or her duties would be regulated by the corporation or partnership, which might not always have the child's best interests at heart. As Solicitor of Labor Richard F. Schubert advised Congressman Walter B. Jones in his letter of September 12, 1972, “' exemption requirement unless the partnership was comprised of the child's parents only or the corporation was solely owned by the parent or parents."

The Department has, for many years, considered that a relative, such as a grandparent or aunt or uncle, who assumes the duties and responsibilities of the parent to a child regarding all matters relating to the child's safety, rearing, support, health, and wellbeing, is a 'person standing in the place of' the child's parent (see letter of Charles E. Wilson, Agricultural Safety Officer, Division of Youth Standards of April 7, 1971 to Mr. Floyd Wiedmeier). It does not matter if the assumption of the parental duties is permanent or temporary, such as a period of three months during the summer school vacation during which the youth resides with the relative (Id.). This enforcement position does not apply, however, in situations where the youth commutes to his or her relative's farm on a daily or weekend basis, or visits the farm for such short periods of time (usually less than one month) that the parental duties are not truly assumed by that relative. The Department also interprets the term 'parent or person standing in the place of the parent' to mean a human being and not an institution or facility, such as a corporation, business, partnership, orphanage, school, church, or a farm dedicated to the rehabilitation of delinquent children.

The Department interprets 'operated by' the parent or person standing in the place of the parent to mean that he or she exerts active and direct control over the operation of the farm or ranch by making day-to-day decisions affecting basic income, work assignments, hiring and firing of employees, and exercising direct supervision of the farm or ranch work. A ranch manager, therefore, who meets these criteria could employ his or her own children under 16 years of age on the ranch he or she operates without regard to the agricultural hazardous occupations orders, even if the ranch is not owned by the parent or a person standing in the place of the parent, provided the work is outside school hours.

It is important to note that a child who is exempt from the Ag H.O.s when employed on his or her parent's farm would generally lose that exempt status (not be exempt) when employed on a farm owned or operated by a neighbor or non-parental relative. This is true even if the youth is operating equipment owned by his or her parent.

None of the revisions proposed in this NPRM in any way change or diminish the statutory child labor parental exemption in agricultural employment contained in FLSA section 13(c)(1). The child labor provisions of the FLSA, just like the Act's minimum wage and overtime provisions, apply only when an employment relationship exists 
between an employer and a young worker. The concept of an employment relationship, which is the same for agricultural and nonagricultural employment, is well established under the FLSA and discussed in detail in Chapter 10 of the WHD Field Operations Handbook (FOH), available at http://www.dol.gov/whd/FOH/FOH_Ch10.pdf and in 29 CFR part 776.

The 1974 FLSA amendments also amended section 13(c) to permit the employment of the following young hired farm workers (the term used to describe youth under the age of 16 who do not fall within the parental exemption) to work outside of school hours in non-hazardous agricultural occupations: (1) One who is 14 or 15 years of age; (2) one who is 12 or 13 years of age and employed on the same farm as his or her parent or person standing in the place of his or her parent, or with the written consent of his or her parent or person standing in the place of his or her parent; and (3) one who is less than 12 years of age and employed with the consent of his or her parent or person standing in the place of his or her parent on a small farm where no employee is required to be paid the minimum wage because of the exception provided by FLSA section 13(a)(6)(A). The Department interprets the term consent to mean written consent. These provisions remain the basic minimum age standards for agricultural employment. Again, it is important to note that the FLSA provides no similar 'take your children to work' exemption for the children of workers employed in nonagricultural employment. Parents cannot waive the nonagricultural child labor provisions for their children unless the parent is the employer; and then, only certain provisions may be waived.

The Fair Labor Standards Amendments of 1977, Public Law 95-151, Sec. 8, added section 13(c)(4). This section allows the Secretary of Labor to consider granting requests for waivers to employers that would permit local minors 10 and 11 years of age to be employed outside of school hours in the hand harvesting of short season crops under certain conditions. The Department issued regulations at 29 CFR part 575 (Waiver of Child Labor Provisions for Agricultural Employment of 10 and 11 Year Old Minors in Hand Harvesting of Short Season Crops) in 1978 and a few waivers were actually granted in the early years. But the Department was enjoined from issuing such waivers in 1980 because of issues involving exposure, or potential exposure, to pesticides (see National Ass'n of Farmworkers Organizations v. Marshall, 628 F.2d 604 (DC Cir. 1980)). Therefore, no waivers have been granted under FLSA section 13(c)(4) for thirty years.

The Department is committed to ensuring that the agricultural youth employment provisions of the FLSA balance the benefits of employment opportunities with the necessary and appropriate safety protections. Changes in the nature, size, and technology of agricultural workplaces, along with the high incidences of occupational injury and death suffered by agricultural workers of all ages, warrant an ongoing review of the youth employment provisions. Before addressing the changes to the agricultural youth 
employment provisions the Department is proposing in this NPRM, it is important to discuss the demographics of the young workers impacted by the proposed changes and the occupational safety and health issues they confront.

Because the parental exemption for agricultural employment is so broad, allowing exempt youth to perform any work at any age (except in manufacturing and mining) and at any time of the day, the Federal child labor provisions generally apply only to youth who are hired farm workers. Although articles and studies concerning young hired farm workers have been issued by many diverse groups, including the Department, the USDA, the Government Accountability Office (GAO), the National Institute for Occupational Safety and Health (NIOSH), the Human Rights Watch, the Farmworkers Justice Fund, Inc., and the Census Bureau, there is consensus that estimating the number of young hired farm workers is difficult because of the gaps in available data. " (FR 76 No 171, Pages 54841-2)

"The Department proposes to revise this section of subpart G to reflect the statutory changes to the FLSA provisions dealing with child labor employment in agriculture that were made since the last update of the subpart. A similar revision of the subpart addressing nonagricultural employment was made by the Final Rule published by the Department on May 20, 2010 (see 75 FR 28404).

The Department proposes to clarify the parental exemption involving agricultural employment by including information about the exemption discussed in the Background section of this preamble. The proposal provides guidance as to who qualifies as a parent; what determines that a farm is 'operated by' a parent; and how the Department interprets the extension of this parental exemption to persons standing in the place of a parent as well as a relative who may take temporary custody of a youth and stands in the place of the parent. The revision also notes that the parental exemption--both in terms of working during school hours and performing hazardous occupations normally prohibited by the Ag H.O.s--would not apply to the employment of a child of a farmer when that child is employed on a farm not owned or operated by his or her parent. It also addresses related situations, such as where the farm or its property may be owned by a closely-held corporation or partnership consisting of family members or other close relatives.

The Department also proposes to incorporate the provisions of FLSA sections 13(c)(2) and 13(c)(1)(A) through (C) into Sec. 570.123. These sections were enacted after the last revision to subpart G. Section 13(c)(2) establishes the Secretary's authority to find and declare certain agricultural occupations to be particularly hazardous for the employment of children below the age of 16 and sets the minimum ages for employment in agriculture. Unlike the parental exemption contained in section 3(1) which exempts only the employment of a youth by a parent or person standing in place of a parent in a 
business/farm solely owned by that parent or person, sections 13(c)(1)(A) and 13(c)(2) expand the parental exemption to include youth who are employed in agriculture by a parent or person standing in place of a parent on a farm operated by such parent or person. The parent/operator of the farm must be the employer of the minor for this exemption to apply. Although section 13(c)(2) permits youth working for their parent(s) or person(s) standing in place thereof on a farm operated by such parent(s) or person(s) to perform hazardous work otherwise prohibited by the Ag H.O.s, section 13(c)(1) limits such employment to periods outside of school hours for the school district where the youth is living while so employed.

The Department's proposal retains the current explanation of the term school hours for the school district where such employee is living while so employed. The Department is proposing to clarify that interpretation by defining graduating from high school as the successful completion of the 12 th grade. This would include the successful completion of a high school general equivalency diploma (GED) program. The Department also proposes to revise its guidance concerning the hiring of children who have moved from one to school district to another. The current regulation suggests that employers not hire such youth prior to May 15th, the Department's proposal would change that to June 1st in recognition of the longer school years now in effect in most of the country. In addition, the proposal would update the acceptable evidence regarding school schedules to permit statements by a school official regarding dates for the beginning and end of the school year or school day in the particular district in question, or report cards or other documents which may be provided to the student by the school." (FR 76 No 171, Pages 54865-6) 


\section{Appendix B: Student Learner Excerpt for DOL Proposal}

As discussed earlier, when the Ag H.O.s were originally adopted as an Interim Order in 1967, the Interim Order contained an exemption for 14- and 15-year-old student-learners who were enrolled in a bona fide cooperative vocational program in agriculture. In 1968, the Department modified the Interim Order to permit 14- and 15-year-olds to drive tractors and operate other farm machinery provided they completed a formal training program in the safe use of such equipment coordinated by the U.S. Department of Agriculture's Federal Extension Service. In 1969, the Interim Order was again amended to permit 14- and 15-year-old vocational-agricultural students to operate tractors and certain machinery after completing training in the safe use of such equipment. These three programs were incorporated into the Final Order issued by the Department on January 7, 1970 (see 35 FR 221) and have remained unchanged for over forty years. It is important to note that children who are employed on a farm owned or operated by their parents are statutorily exempt from the agricultural hazardous occupations orders and may operate a tractor on a farm owned or operated by their parents without having to meet the requirements of any of the above-mentioned exemptions. The revisions the Department is proposing in this NPRM do not change that statutory exemption in any way.

Questions regarding the appropriateness and effectiveness of these exemption programs have been raised since their inception. Section 570.72(d), part of the original regulation issued in 1970, continues to state: 'The provisions of paragraphs (a), (b), and (c) of this section will be reviewed and reevaluated before January 1, 1972. In addition, determinations will be made as to whether the use of protective frames, crush resistant cabs, and other personal protective devices should be made a condition of these exemptions.' Such a review, though never completed, is as important and relevant today as it was in 1970.

Changes in the agricultural industry over the last four decades--including such things as the size, ownership, labor needs, and available labor pools of farms; agricultural machinery and processes; the types and uses of fertilizers and pesticides; the development of agri-tourism; and the improvement in the reporting of occupational injuries and deaths-have fueled interest in these exemption programs from parties both inside and outside of the government.

Many individuals and organizations have questioned whether it is prudent to allow 14and 15-year-old hired farm workers--youth who academically are normally in eighth or ninth grade--to perform tasks that present so many hazards to adult workers of every age and experience level. Among these are the Association of Farmworker Opportunity Programs (see letter of March 25, 2003 from David Strauss, Executive Director, available at http://www.regulations.gov, docket number WHD-2011-0001) and The National Farm 
Medicine Center (see Proposed Changes in the Hazardous Occupations Orders in Agriculture, National Farm Medicine Center [2003], available at http://www.regulations.gov, docket number WHD-2011-0001). They note that much farm machinery is very large and powerful, and that all of it is designed for adult operators. Youth as young as 14 and 15 years of age often have not completed the adolescent growth spurt, placing them at additional risk when they operate or assist in the operation of such machinery or attempt to perform tasks that present ergonomic challenges to their age group. Approximately one-third of all deaths to young agricultural workers can be attributed to tractors, and in about one-half of the cases, the tractor overturned on the youth. BLS Report on the Youth Labor Force [2000], p. 60. Further, involvement with machinery and [[Page 54850]]vehicles each account for 38\% of the deaths of young agricultural workers (see Hard, D., Myers, J., [2006], Fatal Work-Related Injuries in the Agriculture Production Sector Among Youth in the United States, 1992-2002, Journal of Agromedicine, Vol. 11(2), available at http:// ja,haworthpress.com). Helen Murphy, writing in 2007 as the outreach and education director at the University of Washington Pacific Northwest Agricultural Health and Safety Center, notes that annually, more that 100 children who live on, work on, or visit farms, are killed on U.S. farms, with tractors being responsible for 41 percent of the accidental farm deaths of children under 15 years of age (see Tractor Safety Advice Saves Lives, available at http://depts.washington.edu/trsafety/files/P1_Tractor_Advice_Murphy.pdf).

The FLSA does not permit such young workers--14 and 15 years of age--to perform hazardous work with power-driven machinery in nonagricultural employment, and the similar exemptions from the nonagricultural hazardous orders do not apply to anyone under 16 years of age, even if the youth is the child of the employer. In fact, section 13(c)(6) of the FLSA, enacted by Congress in 1998, prohibits any youth under the age of 17 employed in nonagricultural work from driving trucks or automobiles on a public road, and puts strict restrictions on the conditions and amounts of time that 17-year-olds may drive. There are no exemptions from the driving restrictions placed on minors below the age of 17 in nonagricultural employment--and that includes youth who are employed by their parents.

In 2003, the National Farm Medicine Center of Marshfield, Wisconsin, in its comments on the recommendations of the NIOSH Report, advised the Department that no exemptions for hired youth operating tractors should be allowed. 'The current 4-H and vocational agriculture tractor and machinery certification programs have not been subjected to sufficient evaluations to confirm their effectiveness in preparing youth to safely operate tractors. Furthermore, state-by-state variability in certification administration makes it inappropriate to base Federal exemptions on this certification' (see Position Statement: Proposed Changes in the Hazardous Occupations Orders in 
Agriculture, National Farm Medicine Center [2003], available at http://www.regulations.gov, docket number WHD-2011-0001).

Questions have also been raised as to whether 14- and 15-year-old hired farm workers in general are capable of possessing and practicing the continuous level of safety awareness that is necessary in such a dangerous occupational environment as agriculture. Many studies have noted that young workers are not 'little adults' but human beings at their own unique stage of development. It is well established that several characteristics of youth place adolescent workers at increased risk of injury and death. Lack of experience in the workplace and in assessing risks, and developmental factors--physical, cognitive, and psychological--all contribute to the higher rates of occupational injuries and deaths experienced by young workers. Many of the physical and cognitive limitations of young workers cannot be overcome by training or supervision. See Sudhinaraset, M., Blum, R., [2010]. The Unique Developmental Considerations of Youth-Related Work Injuries, International Journal of Environmental Health; 16-216-22. See also NIOSH Alert Preventing Deaths, Injuries, and Illnesses of Young Workers, available at http://www.cdc.gov/niosh/docs/2003-128/2003128.htm; NIOSH Report, page 6; Casey B, Getz S, Galvan A, [2007]. The Adolescent Brain, available online at http://www.sciencedirect.com. These risks associated with employment are heightened when the youth are working in agriculture because the work itself is more dangerous and the ages of permissible employment are so much lower than in nonagricultural employment. For example, there is no minimum age established for employment on small farms not subject to the minimum wage requirements of the Fair Labor Standards Act (see 29 U.S.C. 213(c)(1)).

A study of the effectiveness of tractor certification found that many youth who completed the training in Indiana self-reported that while they felt the training did make them safer operators, they also reported engaging in a number of risky behaviors including not wearing seat belts with roll-over protection structure (ROPS)-equipped tractors and allowing extra riders (see Carrabba Jr. JJ, Talbert BA, Field WE, Tormoehlen R [2001]. Effectiveness of the Indiana 4-H Tractor Program: Alumni Perceptions. Journal of Agricultural Education, vol. 42, Issue 3). Another study found that some youth working in agriculture, even after acquiring increased safety knowledge, still were dangerous risk takers (see Westaby JD, Lee BC [2003]. Antecedents of injury among youth in agricultural settings: A longitudinal examination of safety consciousness, dangerous risk taking, and safety knowledge. Journal of Safety Research, 34 [2003] 227240).

In its Report, NIOSH notes that " $[\mathrm{t}]$ he effectiveness of these tractor safety training programs has not been adequately evaluated nationwide" (see Report, page 70). NIOSH does state that the Carrabba study in Indiana to determine the impact of 4-H tractor safety 
programs on the behavior and attitudes of young tractor operators found that participants demonstrated a greater level of confidence in operating tractors, and that the program appears to have a positive influence on the safe operating procedures of participants. However, as noted above, the Carrabba study also found that, despite the youths' feelings of confidence, they continued to engage in risky behaviors such as allowing extra riders. NIOSH also mentioned a study in Wisconsin that found that youth who had completed a training program reported an increase in usage of tractors equipped with roll-over protection structures (see NIOSH Report, page 71). These few studies demonstrate the need for a much closer and more thorough examination of the effectiveness of tractor safety training for children. In light of the fatality and injury data demonstrating the hazardous nature of working on tractors and other power-driven equipment, until such information is available, the Department must reconsider whether it is consistent with the Secretary's statutory mandate to allow certain 14- and 15-year-olds to operate tractors based on the efficacy of such training.

The Department is concerned that the training and skill sets that youth must complete in order to receive certification under the limited exemptions contained in Sec. 570.72(b) and (c)--which allow 14- and 15-year-old hired farm workers to operate tractors and several types of farm implements and have not been modified since their creation in 1971--are not sufficiently extensive and thorough to ensure the safety of young hired farm workers. The Federal Extension Service tractor certification requirements, as detailed in Sec. 570.72(b)(1), call for only a ten-hour training program, which includes the completion of 'units' that are no longer available. Upon completion of these 'units' the minor need only pass a written examination and demonstrate his or her ability to operate a tractor safely with a two-wheeled trailed implement on a course "similar to one of the 4-H Tractor Operator's Contest Courses." Under the regulations at Sec. 570.72(b)(2), the youth need only complete an additional ten hours of course work, pass a written examination on tractor and farm machinery safety,[[Page 54851]] and demonstrate his or her ability to operate a tractor with a two wheeled trailed implement, again, on a course similar to one used in 4-H Contests, in order to qualify for exemption with regard to other farm machinery. Neither program requires any ongoing or periodic supplemental training or instruction. This may be problematic for many reasons, but especially because of the extremely wide variety of sizes, ages, operation protocols, and types of farm equipment and tractors used on American farms. The Department is concerned that twenty hours of classroom training is insufficient to provide a young hired farm worker with the skills and knowledge he or she would need to safely operate the diverse range of agricultural tractors and equipment in use on today's farms. The Department notes that most state graduated motor vehicle driver licensing programs require considerably more training and operating experience--some as much as 96 hours-- 
and that such training is for youth who are at least 16 years of age and only operating a single piece of equipment (see Insurance Institute for Highway Safety Licensing Systems for Young Drivers available at http://www.iihs.org/laws/graduatedlicenseIntro.aspx; see also http://www.mva.maryland.gov/Driver-Safety/Young/safety.htm). Similar requirements and problems exist in regards to the vocational agricultural training exemption, the requirements of which are contained in Sec. 570.72(c).

The Department is also concerned that there has been almost no monitoring by any government agency to ensure the integrity and effectiveness of these certification programs. In an evaluation of the Wisconsin certification process, the authors note that "the evaluation and monitoring of these programs for effectiveness has been nearly nonexistent" (see Schuler RT, Skjolaas CA, Purschwitz MA, Wilkinson TL [1994]. Wisconsin youth tractor and machinery certification programs evaluation. ASAE Paper No. 94-5503. St. Joseph, MI.). The 2001 article on the Indiana 4-H Tractor Program (see Carrabba Jr. JJ, et al.) also noted that "a review of the literature did not uncover any research that has specifically evaluated the effectiveness of the 4-H Tractor Program, as a safety intervention, at either a state or national level." The Department believes it would not be consistent with the Secretary's mandate to allow certain 14- and 15-year-olds to operate tractors and farm equipment until the evidence demonstrates that such youth are not at risk and can perform all the associated tasks safely. The Department asks for comment regarding any data or studies relating to the efficacy of these programs and their impact on the ability of 14- and 15-year-olds to operate tractors and farm equipment safely and to perform the associated tasks safely.

In addition, because the actual certification occurs at the local level, the content and quality of the training is often determined by the instructor who conducts the training (see Carrabba Jr. JJ, et al.). The written examinations are not standardized and large differences have been noted in what constitutes a passing grade. Differences also exist in how youth actually perform the required practical demonstration of safe tractor and machinery operation as well as how their performances are evaluated. The Department has also uncovered at least one instance in which youth were issued certificates without receiving the proper training or completing the required testing.

Finally, the Department is aware of concerns that the certification programs may not be reaching young farm workers who need such training to legally be employed in work that would otherwise be prohibited by certain of the Ag H.O.s. Certification programs are not available in many areas of this country because of the lack of such things as interest, need, qualified and available instructors, and resources. A 2006 article reported that extrapolating from $4-\mathrm{H}$ records and Ohio census data, fewer than $1 \%$ of the youth in Ohio who were operating tractors or other hazardous machinery had participated in tractor certification training (see Heaney JR, Wilkins III CA, Dellinger W, McGonigle H, Elliot 
M, Bean TL, Jepsen SD [2006]. Protecting Young Workers in Agriculture: Participation in Tractor Certification Training. Journal of Agricultural Safety and Health. 12(3): 181190). Another study notes that, nationally, the 4-H Tractor program has been one of the smallest 4-H education programs, with less than 21,500 participants enrolled in 1997 (see Carrabba, Jr., JJ, Talbert, BA, Field, WE, Tormoehlen, R [2001]. Effectiveness of the Indiana 4-H Tractor Program: Alumni Perceptions. Journal of Agricultural Education. 42: 11).

The Department is requesting comments as to whether 14- and 15-year-old hired farm workers are capable of absorbing, and implementing on a continuous basis, the knowledge necessary to ensure their safety and the safety of others while performing tasks otherwise prohibited by the Ag H.O.s. Therefore it is asking for public comment as to whether the child labor provisions should permit any hired farm worker under the age of 16 years to operate or assist in the operation of agricultural tractors or agricultural implements.

But if such youth are capable of mastering the skills necessary for safe tractor and implement operation, it would seem that the training that delivers this knowledge must be extensive, thorough, and have immediate relevance to the tasks the youths will be performing once the training is completed. Given the diversity and seasonality of so many farm activities, it would seem that such training would have greater continuous impact if it were ongoing throughout the youth's employment rather than limited to a single demonstration of a single specific task, such as driving a tractor, which may be completed even before the youth is 14 years of age and eligible for employment.

Accordingly, the Department is proposing to remove the exemption for 14- and 15year-old hired farm workers who have received certification under the auspices of the Federal Extension Services contained at Sec. 570.72(b). It also proposes to remove the exemption for 14- and 15-year-old hired farm workers who have received vocational agricultural training contained at Sec. 570.72(c). The revocation of these two exemptions is intended to place immediate limitations on the employment of 14- and 15-year-old hired farm workers, even if they had completed their certification prior to the effective date of any final rule implementing this proposal, since the exemptions would no longer exist. Such youth could only continue to perform work prohibited by the Ag H.O.s if they were employed by a parent on a farm owned or operated by that parent in accordance with the parental exemption, or as a student-learner employed under the provisions of the proposed Sec. 570.98(b).

In order to foster the continuous and thorough training it believes is necessary to protect young hired farm workers, the Department proposes to both retain and revise the student-learner exemption currently located at Sec. 570.72(a), and move it to a proposed Sec. 570.98(b). Under the Department's proposal, a student-learner must 
be enrolled in an ongoing vocational education training program in agriculture operated by a state or local educational authority, or in a substantially similar program conducted by a private school. It is the Department's position that the 14- or 15-year-old studentlearner must be properly enrolled and participating in the vocational education training [[Page 54852]]program throughout his or her agricultural employment in order to take advantage of this exemption. Such a program could not be completed prior to the youth's sixteenth birthday and satisfy the conditions of this exemption.

In order to ensure the student-learner has obtained sufficient safety training and practical knowledge before he or she is permitted to be employed as a hired farm worker performing otherwise prohibited work under this exemption, the student-learner must first successfully complete at least 90 hours of systematic school instruction in agricultural education at or above the eighth grade level. It is important to note that not having the prerequisite 90 hours of systematic school instruction in agricultural education would not preclude the employment of a 14- or 15-year-old as a hired farm worker, but it would prohibit that youth from performing any work prohibited by an Ag H.O.

The Department believes that 90 hours is equivalent to an academic semester and that the curriculum would include a combination of classroom, virtual, and hands-on training appropriate to prepare the youth for agriculture as a vocation. It is anticipated that school systems in areas of high demand for agricultural vocational training would provide such vocational training as a part of the school's curriculum, at no cost to the student, or in the case of a private school, no additional cost to the student. The Department welcomes comments from school boards and school systems on the extent to which such training is already included in their curriculum, the extent to which existing agricultural vocational training programs would need to be modified to meet the requirement and whether an academic semester is an appropriate period given the maturity level of the youth in general.

In addition, when employed as a hired farm worker performing otherwise prohibited work under the exemption, the proposal provides that the student-learner must be employed under a written agreement which provides that: (1) The work of the studentlearner in the occupations declared particularly hazardous is incidental to his or her training; (2) the work will be intermittent, for short periods of time, and under the direct and close supervision of a qualified and experienced adult who is at least 18 years of age; (3) safety instruction shall be given by the school and correlated by the employer with on-the-job training; and (4) that a schedule of organized and progressive work processes to be performed on the job has been prepared and implemented. Such written agreement shall contain the name of the student-learner and be signed by the employer, the parent or guardian of the student-learner, and a person authorized to represent the educational authority. Copies of the signed written agreement shall be kept on file by both the 
educational authority or school and by the employer before the student-learner may be employed to perform work that would otherwise be prohibited by this subpart.

The Department is also proposing to limit the types of otherwise prohibited work which bona fide student-learners may perform under the authority of the exemption. Currently, such student-learners may be employed to perform work otherwise prohibited by Sec. 570.71(a)(1) through (a)(6) (the first six Ag H.O.s). This proposal would limit the student-learner to the first two Ag H.O.s as revised by this NPRM. The application of the student-learner exemption to each of those revised Ag H.O.s will be discussed in those sections of this preamble dealing with each of those $\mathrm{Ag} \mathrm{H.O.s.}$

Despite proposing to remove the limited certification exemptions for hired farm workers, the Department believes such training programs provide important training and safety development opportunities to the young farm workers who are the children of and employed by those who own and/or operate farms. These programs may be the only formal training in such skills that these youth ever receive, as they are exempt from the Federal Ag H.O.s by virtue of the parental exemption contained in FLSA section 13(c)(2). These programs also can continue to provide important training to youth who are not student-learners but who wish to seek employment as hired farm workers and will be able to legally operate such equipment, under current law, once they reach their sixteenth birthday.

The Department is aware that the USDA's National Institute of Food and Agriculture (NIFA), formerly the Cooperative State Research, Education and Extension Service (CSREES), shares many of its concerns and has been working diligently over the last several years to implement changes to the certification process to ensure that young agriculture workers can obtain meaningful and effective safety training. Through its Youth Farm Safety Education Certification Program (formerly Hazardous Occupations Safety Training for Agriculture (HOSTA)), NIFA has funded programs in such areas as identifying the skill-sets needed by youth for non-parental farm employment; developing a curriculum for the training; exploring various media for delivering such training; creating a model for the development, implementation, and evaluation of an administrative management system for certification; and management of instructor selection, training, and authentication. The Department appreciates the achievements of NIFA and will continue to work with that agency to assist in its efforts. (FR 76 No 171, Pages 54850-3) 


\section{Appendix C: Against Form Letter 1, "May Seem Logical”}

"I am writing to express my strong concern over the United States Department of Labor's proposed rule, "Child Labor Regulations, Orders and Statements of Interpretation" (RIN 1235-AA06), which will change the list of prohibited occupations for minors in agricultural employment. While updating the laws would appear reasonable, these proposed changes will restrict the ability of my farm to employ youth who want to develop job skills and strong ethics.

I am very concerned about the changes to the student learner program. One way we ensure safe domestic food is by encouraging early involvement in agriculture, frequently through participation in a student learner program. Many farmers choose an agricultural career because of their exposure to farming while employed as a youth. The restrictions proposed on the student learner programs are troubling. If enacted they will reduce on-farm learning opportunities and decrease interest in agricultural careers among our youth.

Also, restricting the "parental exemption" rule poses a serious risk for our farms. The majority of farms are still family run but now involve ownership tiers with related partners. It doesn't make sense that a farmer's own niece or nephew, even with parental permission, would be denied the opportunity to participate in the family farm.

While it may seem logical to propose these changes it would severely limit the ability of my farm to employ youth in a meaningful way. The restrictions on the ability to work with animals - which go far beyond current successful protections - along with several other dramatic changes in field employment, will restrict the ability to employ youth on my farm. It will deny our children the opportunity to decide whether or not they would ultimately like to have a career in agriculture.

I strongly oppose these proposed regulations and respectfully request that you consider their negative impact upon agriculture." 


\section{Appendix D: Against Form Letter 2, "Colorado Farm Bureau Member"}

"As a member of Colorado Farm Bureau, I am writing these comments in response to the above-captioned rulemaking. In my view, $\mathrm{HO}$ \#1 would effectively prohibit youth from operating tractors in all situations, even in instances when such operation is not particularly hazardous. The practical effect of the revised $\mathrm{HO}$ will reduce legitimate opportunities for employment and training for youth on farms. Under HO\#2 will result in extreme prohibitions. For example, simple devices such as a hand-held screwdriver, a weed-whacker, a lantern or a flashlight can be battery-powered. According to the department's proposal, because these devices are powered by a 'power source other than human hand or foot power,' presumably, they are all prohibited. HO\#4 would greatly reduce youths' exposure to livestock and animal husbandry practices. These activities have been performed for generations in America. Youth engage in many activities that entail some risk, injury and in extreme cases fatality. To impose a Federal prohibition on an activity that has a long history of tradition is regulatory over-reach. HO\#8 would prohibit occupations involving working inside any fruit, forage, or grain storage silo or bin. This proposal has established parameters that make the regulation too vague and encompassing. For instance, it is not clear what constitutes storage. Does forage storage apply to hay barns? Would 'fruit storage' include a bushel crate or bin? Would this provision apply to a grain elevator that has overhead bins? While this proposed rule does exempt the farm youth of parents whom own or operate $100 \%$ of an agricultural operation, this does not reflect the reality of agriculture today. In many agriculture operations, multiple family members are part owners of an operation. Under this rule, because no single family owns or operates $100 \%$ of a farm or ranch, then none of their children would be allowed to work. I appreciate the opportunity to comment on this proposed rule." 


\section{Appendix E: Against Form Letter 3, "Blanket Prohibition"}

"As a farmer, I am concerned about the Department of Labor child labor rule, "Child Labor Regulations, Orders and Statements of Interpretation" (RIN 1235-AA06).

A blanket prohibition on youth employment in agriculture has never been approved by Congress, and the Fair Labor Standards Act has drawn a distinction for over 70 years between employment in agricultural and nonagricultural jobs. The proposed rule comes close to eliminating nearly every farm job for youth.

The activities on modern farms are tough, but defining nearly every job on a farm as a hazardous occupation is beyond reason. The rule limits the development of a solid work ethic commonly attributed to those that grow up and work on farms. The rule will also have a dramatic change on current agricultural practices by limiting young family workers from learning how to manage a farm.

Narrowing the family exemption for on farm youth tears at the very fabric of farm life and is not directed by Congress in any way. Family ownership of farms is unique. Organization of the family farm is typically more than just a single individual. It can be driven by transitioning the family farm from one generation to the next or other business succession decisions. The rule would undermine the traditional extended family farm by limiting the ability of children, grandchildren, nieces and nephews to participate in and learn the family business.

Farming occurs almost exclusively in rural communities, where it has traditionally been a way of life for extended family to participate in operating the farm. This is truer today, when family and estate planning have operated in such a way as to alter the ownership patterns and operational plans of farms. Often, in order to keep the farm in the family, relatives will enter into joint operating agreements, partnerships, limited liability corporations, trusts or other entities in order to assure the continued operation of the farm and the involvement of siblings and their heirs. The rule's interpretation of the parental exemption is in direct conflict with today's farm organization structure.

The proposed rule will limit, if not eliminate, opportunities to teach youth in agriculture. Many rural areas do not have vocational agriculture programs available nor the funding to provide them. The proposed rule should continue to allow students to learn through 4-H, FFA and Extension while they are working in agriculture.

As a farmer, I believe the proposed rule will reduce or eliminate virtually all farm work opportunities for youth under 16 and I believe the rule should be withdrawn." 


\section{Appendix F: Against Form Letter 4, "Confusing, Duplicative, and Unnecessary"}

"Wage and Hour Division

U.S. Department of Labor

Room S-3502

200 Constitution Avenue, NW

Washington, DC 20510

\section{RIN 1235-AA06}

\section{To Whom It May Concern:}

I am concerned about the Department of Labor child labor rule, 'Child Labor Regulations, Orders and Statements of Interpretation' (RIN 1235-AA06). This rule will have a dramatic change on current agricultural practices by limiting young family workers from learning how to manage a farm. The activities on a modern farm range from planting, harvesting, collecting fruits and vegetables, caring for animals, and operating tractors and other equipment, among other activities.

Ownership of the family farm partnership is unique. In many instances ownership of the family farm has changed as land has passed from one generation to another with multiple family members owning, operating and being employed by the farm. The rule would undermine the traditional extended family farm by limiting the ability of grandchildren, nieces and nephews to learn the family business.

Agricultural operations offer an exceptional work opportunity for all, including youth. Farms offer a unique opportunity to train, educate and provide resources for young workers and their families in rural communities. Currently, there are protections for workers on farms and this rule is confusing, duplicative and unnecessary." 


\title{
Appendix G: Against Form Letter 5, “Agricultural Educator"
}

\author{
Prepared by Kent Schescke, National FFA Organization, and Jay Jackman, National \\ Association of Agricultural Educators, to Assist School-based Agricultural Educators
}

I am submitting these comments in response to the above-captioned rulemaking. I am grateful for the opportunity to comment on the U. S. Department of Labor's proposal and to point out the potential damaging impact this proposal would have on the agriculture industry.

[Add a paragraph about yourself and your role in agricultural education. Tell where you teach, how many students you have, what you teach related to farming, the numbers of your students who work for pay on farms, how you incorporate farm safety instruction in your classes, and whatever else you determine to be important and appropriate.]

I will provide some general comments on the proposed rulemaking, specific comments related to the role of school-based agricultural education in teaching students who may have opportunities to work on farms, and some specific comments on the proposed rule.

\section{General Opening Comments}

I have no interest or desire in placing youth at risk on the farm. I support existing provisions in the Fair Labor Standards Act (FLSA) that permit the U.S. Department of Labor to establish appropriate standards for youth employment on the farm, restricting jobs in which youth may engage to those that are not "particularly hazardous."

Many students have opportunities to work on family farms that may, or may not, be owned by their parents/legal guardians. Farms owned by grandparents, uncles/aunts, siblings, and other relatives provide excellent opportunities for students to gain work experience in agriculture. Neighbors may provide excellent work experience opportunities to students as well. I am appreciative of the parental exemption in the current regulations. However, this exemption should be expanded to include farms owned by other relatives, neighbors, and even corporations as long as the parent/guardian of the student approves of the work experience opportunity for the student.

A major concern with the proposed changes to the child labor regulations is that these changes will limit, if not eliminate, our opportunities to TEACH students to be safe when working in agriculture. If the proposed rules go into place unchallenged, most of these learning opportunities would be lost or seriously compromised. Please allow us to continue to TEACH students to be safe while receiving relevant work experience in agriculture.

We appreciate the recognition of the education and training our agricultural education programs provide students. The current regulations make this central to the application 
of the law; however, the proposed regulations and expanded Hazardous Occupation areas (H.O.'s) either do not include the student learner exemption, or they limit severely the opportunities for students enrolled in agricultural education programs to be involved. I believe it is more responsible to teach students to be safe, rather than to tell them, "Don't do that, you might get hurt."

Students working for pay on farms, under the supervision of the highly qualified and certified agriculture teacher, is an example of the Supervised Agricultural Experience (SAE) program, which is the key experiential learning component of the agricultural education model.

Written SAE agreements can, and should, be signed by the employer, the student, and the teacher. Appropriate instruction, including safety instruction, is to be included in the SAE agreement.

I am particularly concerned about how the Student Learner Exemption is treated in the proposed rule. The existing provisions of the Fair Labor Standards Act (FLSA) provide an exemption for students enrolled in vocational training in agriculture. Today, those programs are referred to as school-based agricultural education and are a part of career and technical education. Nearly a million students are enrolled in these programs across the United States and its territories. Some 7,500 such programs are available through primarily public high schools, and instruction is provided by 11,000 highly qualified teachers certified to teach agriculture. These programs play a critical role in educating young people and introducing them to careers in agriculture and agricultural science.

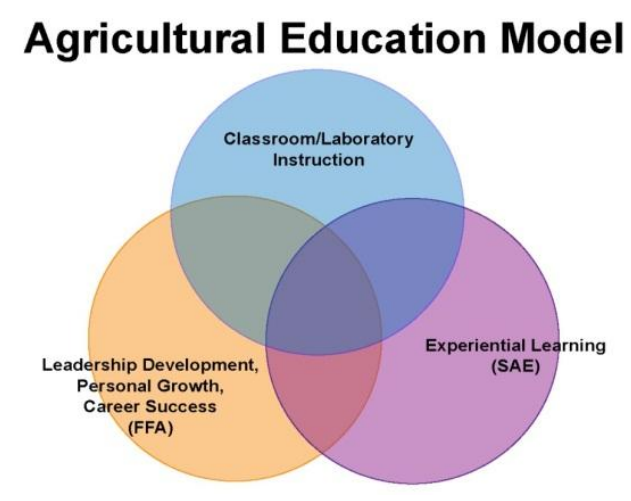

Since its inception nearly a century ago, the model of delivering high-quality, effective instruction in agriculture has been centered around three critical integral components. First is the classroom/laboratory setting in which students receive formal academic, hands-on instruction related to agricultural sciences. These courses are organized sequentially and offer students opportunities to explore myriad career options as they learn science, technology, engineering and mathematics (STEM) through the applied 
context of agriculture, food and natural resources. Safety education has always been, and continues to be, an important part of the classroom and laboratory instruction.

The second component is experiential learning, also referred to as supervised agricultural experience, or SAE. This part of the program takes place predominately outside of the classroom and school, but it is supervised by the agricultural instructor. Supervised agricultural experience programs come in many forms, including entrepreneurship, placement (at a job site), research and service-learning. While historically many of our students come from farms, today a large number, roughly two-thirds, do not have that opportunity. These students are very interested in learning about agriculture. The experiential learning programs, especially in placement job settings, provide invaluable opportunities for students to learn the application of what is taught in the classroom/laboratory environment. A recent review of supervised agricultural experiences showed that one in three students received their experiential learning through placement experience.

The third component is leadership, citizenship and personal growth that is taught through the National FFA Organization. FFA, a student organization formerly known as the Future Farmers of America, not only helps students grow as leaders and productive citizens, it also provides students opportunities to maximize learning from both the classroom/laboratory and supervised agricultural experience environments.

Agricultural educators go above and beyond to help students succeed. They care deeply about their students, regarding their safety. That is why agricultural education programs place strong emphasis on teaching safety and ensuring students understand how to apply these lessons in the real world.

A major concern with the proposed changes to the child labor regulations is that these changes will limit, if not eliminate, our opportunities to TEACH students to be safe when working in agriculture. If the proposed rules go into place unchallenged, most of these learning opportunities, especially those that take place in the first two years of the instructional program, would be lost or seriously compromised. A recent sample of supervised agricultural experience data across several states indicated that 36 percent of first and second year agricultural education students were involved in agricultural placement type supervised agricultural experiences. Please allow us to continue to TEACH students to be safe while receiving relevant work experience in agriculture.

The school-based agricultural education community (students, teachers, parents, state supervisory staff and other industry stakeholders) and the supporting agricultural community have serious concerns about many of the proposed rule. Because the majority of the students we serve begin their involvement in agricultural education at age 14, the proposed rule would severely limit or eliminate opportunities to participate in the experiential learning aspects of our program. 
We appreciate the recognition of the education and training our programs provide students. The current regulations make this central to the application of the law; however, the proposed regulations and expanded Hazardous Occupation areas (H.0.'s) either do not include the student learner exemption, or they limit severely the opportunities for students enrolled in agricultural education programs to be involved. We believe it is more responsible to teach students to be safe, rather than to tell them, "Oh don't do that, you might get hurt."

Ultimately, we are concerned about the limits these rules provide on the ability and opportunities for our students to learn by doing. "Learning by doing" is a critical part of the preparation and education through which we prepare students for careers in agriculture and related occupations. In addition, if these rules go into place, what reason or incentives do our teachers have to continue to place such a heavy emphasis on safety?

Agricultural education teachers realize they have a responsibility to work with their students, provide supervision, deliver safety instruction and work with employers of students so that the supervised agricultural experience is educational, meaningful and safe. They also recognize the role they must play in working with the students' parents, employers and student themselves to have well-documented training agreements that clearly identify appropriate Ag H.O. and safety requirements.

We reiterate the commitment and concern we share for the safety of our students. We believe that through education, safety instruction and supervision, we provide safe learning environments for students that help them succeed in the industry of agriculture. This is important to our communities, our states and the nation. Please allow us to continue to TEACH students to be safe while learning and working in agriculture.

\section{Hazardous Occupation Order \#1}

The department seeks to "retain and expand" Ag HO1 by removing the 20 PTO horsepower threshold; requiring that tractors operated by 14- and 15-year old studentlearners be equipped with roll-over protective structure (ROPS); mandating seatbelt use by student-learners; requiring student-learners to have a valid state driver's license if operating tractors on public roads; and prohibiting use of most electronic devices.

This HO expansion would effectively prohibit my students from operating tractors in most situations, even in instances when such operation is not particularly hazardous. The practical effect of the revised $\mathrm{HO}$ would be to reduce legitimate opportunities for employment and training for youth on farms, making it more difficult to educate and train future farmers in agricultural practices. Why would the U. S. Department of Labor wish to limit my ability as an agriculture teacher to teach my students to be safe?

\section{Hazardous Occupation Order \#2}


I believe some equipment may be inappropriate for operation by youth at certain ages and the department may classify such equipment. As proposed, however, the rule is overbroad, mandating "restrictions on the operation of power-driven machinery consistent with those applied to nonagricultural employment." The term "operating" includes "cleaning, oiling and repairing" of the equipment; "connecting or disconnecting an implement or any of its parts to or from such equipment;" or "any other activity involving physical contact associated with the operation or maintenance of the equipment." The term "power-driven equipment" is defined by the department to include "all machines, equipment, implements, vehicles, and/or devices operated by any other power source other than human hand or foot power."

The department's proposal, taken on its face, will result in extreme prohibitions. For example, simple devices such as a hand-held screwdriver, a weed-whacker, a lantern or a flashlight can be battery-powered. Are they prohibited? Is there a blanket prohibition on cleaning any powered equipment (refrigerators, automobiles, etc.)? According to the department's proposal, because these devices are powered by a "power source other than human hand or foot power," presumably, they are all prohibited ... and such prohibition goes too far.

The HO states that "farm field equipment means implements, including self-propelled implements, or any combination thereof used in agricultural operations." This would appear to include both powered and non-powered implements and when a non-powered implement is connected to a powered implement or tractor, any physical contact would be prohibited.

The department's proposal thus would prevent a youth from placing picked fruit or vegetables on a wagon, from hauling hay or picking rocks. It would prohibit the youth from riding an asparagus cart, operating a wiggle hoe or utilizing a powered pruner.

The prohibition of having physical contact with a vehicle presumably would prohibit the hand loading or unloading of materials, tools or products onto pickups or trucks if the "operation" of the vehicle would include the preparation for operating.

\section{Hazardous Occupation Order \#3}

This proposal by the department prohibits "operating and assisting in the operation of hoisting apparatus and conveyors that are operated either by hand or by gravity." Similar broad definitions of terms are employed in the proposal.

It seems to me that the department in this $\mathrm{HO}$ has actually increased, rather than reduced, risk. For example, a hand cart is a mechanical device that applies leverage by hand and foot power to hoist or lift a load and lowers the load by gravity or by hand or foot. It is foolish for the department to use a broad brush in an effort to "protect" youth and in so doing actually increase the risk of injury. Perhaps the department would be willing to 
designate specific devices that should be prohibited, rather than to attempt to ban all activity.

\section{Hazardous Occupation Order \#4}

The department broadly expands the previous agricultural $\mathrm{HO}$ related to working with animals. The impact of the $\mathrm{HO}$ on working with livestock would be to greatly reduce my students' exposure to livestock and animal husbandry practices. Among the notable tasks the proposed HO would prohibit youth from performing are: engaging or assisting in animal husbandry practices that inflict pain upon the animal and/or likely to result in unpredictable animal behavior; treating sick or injured animals; and herding animals in confined spaces such as feed lots or corrals or on horseback.

My students gain valuable hands-on experience working on farms and ranches with animals. In fact, working with animals attracts many students to agriculture. I teach my students proper animal handling practices and animal husbandry practices to keep animals healthy. The student learner exemption is very appropriate regarding this HO.

\section{Hazardous Order \#5}

The preamble states that "for purposes of this Ag H.O. timber means trees, logs, and other similar woody plants. However, this $\mathrm{HO}$ would not prohibit a hired farm youth from performing such tasks as carrying firewood or clearing brush." As drafted, the HO may have the effect of mandating an outright prohibition of youth working in Christmas tree farms or in plant nurseries. It should be clarified to allow such occupations, which are not particularly hazardous. It also should be clear that it does not prohibit youth from ordinary, non-hazardous activities connected with trees (e.g., pruning).

\section{Hazardous Order \#7}

Limiting students from working on elevated structures over six feet high seems quite unreasonable and unfounded. This means my students cannot climb into the cab of a combine or even perform routine maintenance on such a machine. Where do barn lofts fit into this $\mathrm{HO}$ ?

Under this proposed $\mathrm{HO}$, my students would not be able to work on ladders to do many things that range from changing a light bulb to working on large equipment. It will also inhibit many students from helping farmers with the harvest, especially when it requires the worker being more than six feet above an elevation.

\section{Hazardous Order \#8}

This HO would prohibit occupations involving working inside any fruit, forage, or grain storage silo or bin. I recognize that some such occupations could be particularly 
hazardous for my students, I believe as proposed the department has established parameters that make the regulation too vague and encompassing. For instance, it is not clear what constitutes storage. Does forage storage apply to hay barns? Are pole barns that may be used to store overflow grain and empty bunkers covered? Would "fruit storage" include a bushel crate or bin? An un-sided empty bin storage structure? A walk-in cooler at a farm stand? Alternatively, would this only apply to storage containers that maintain a hazardous atmosphere? Clearly, clarification is needed with this proposed HO.

\section{Hazardous Order \#13}

This HO would prohibit all work involved in the production and curing of tobacco. Many jobs involved with the production and curing or tobacco are not particularly hazardous. If it is the goal of the department to assure that youth avoid situations in which they can contract green tobacco sickness (GTS), the department should tailor its regulation to address those situations, and not regulate a blanket prohibition.

\section{Closing Statements}

Please don't limit my opportunities to encourage and assist my students to become farmers. Please do not limit the opportunity we provide students through experiential learning which isis critical to their development toward careers in agricultures. Allow me to teach them about farming and ranching, especially farm and ranch safety, as a part of my agricultural education program in my public school.

Supervised agricultural experience programs are a key component of school-based agricultural education. Placement SAE programs allow students to be paid while learning farming practices, including farm safety.

By teaching students farm safety as a part of my instructional program, I am much more effective in keeping students safe rather than telling them not to engage in farm work.

The student learner exemption for all Ag HOs should be maintained so that I can continue to teach students to be safe while working on farms and ranches.

Sincerely,

[Agricultural Educator] 


\section{Appendix H: Against Form Letter 6, "Let Me Be Clear"}

"Everyone in my family has a job that helps ensure the success of our family farm. For example, my kids help with livestock, shovel out grain bins, paint buildings and mow the lawn. They will no longer be able to fulfill those roles and many others if the Department of Labor enacts new rules restricting children who work on farms (RIN 1235-AA06).

Let me be clear. Nothing is more important to me than the safety of my family and others who work on my farm. Teaching my kids about hard work and the skills they'll need to farm safely if they choose to farm when they grow up is also important.

The Department of Labor needs to understand that while the vast majority of U.S. farms today are family owned and operated, many of those family farms are organized as partnerships and corporations involving brothers, sisters, grandparents, and others. The Department's proposed rules would prohibit children in those families, families like mine, from practically all farm work.

The Department's proposed rules would also prevent me from hiring neighbor kids or relatives to work with me on the farm. Children would be barred from even the most basic chores on the farm. That's unfortunate because I know they benefit from the experience and my supervision, especially the kids who want to pursue farming as a profession.

We can ensure safety on the farm without the Department of Labor's proposed rules. We don't need to choose between safety and teaching the next generation of farmers or ensuring the continued viability of today's farms." 


\section{Appendix I: Against Form Letter 7, “Unintended Consequences"}

"Wage and Hour Division

U.S. Department of Labor

Room S-3502

200 Constitution Avenue, NW

Washington, DC 20510

RE: RIN 1235-AA06, Department of Labor's proposed rule on child labor

\section{To Whom It May Concern:}

I am writing in regards to the Department of Labor's proposed rule on child labor (RIN 1235-AA06). While I support a safe-working environment for all workers including youth, I also feel the Department of Labor's efforts at addressing this issue will result in unintended consequences for America's youth.

As a producer of , I have seen first-hand the benefits youth receive from working on an agricultural operation. Agricultural labor provides youth the opportunity to develop technical skills, character, responsibility, and a work ethic often absent from other jobs available to youth. These skills will serve them well beyond the farm as they embark on careers in other industries and professions. As a result, this rule does in fact protect youth, but rather inhibits their ability to succeed.

Current law and regulations already protect our youth working in agricultural fields. Many parts of this rule represent regulatory over-reach. Agricultural producers want our youth safe but we also want them to grow into successful, hardworking and competent adults. Many of these qualities arise out of working on an agricultural operation. I strongly encourage you to no implement this proposed rule.

Sincerely, 


\section{Appendix J: Pro Form Letter 1, "Changes are Long Overdue"}

Nancy Leppink

Depuly Adninistrator, Wage \& Hour Division

U.S. Department of Labor

200 Constution Avenua NW, $\$-3510$

Washington, DC 20210
November 1, 2011

\section{RE; RIN 1235-AM06 - Proposed Changes to the Agricultural Child Laber Reguations}

Dear Deputy Administrator Leppink:

I am writing to express my strong support for the proposed improvements to the Agricultural Hazardous Occupations Orders published in the Federal Register on September 2, 2011. These changes are long overtue. As the preamble to this proposal so theroughly describes and documonts, children working in agriculure sustain high numbers of injurias due to the hazards encourtered in this industry. These injuries and fatalites are preventable by removing chidren from such dangerous jobs. It is vitally important that children of all ages, especialy those under age 16, are probected from hazardous condijons at work. There is abundant scientiflc evidence demonstrating that the human brain and cognifive function are nol fuly dereloped unti individuals are in their 20s. Knowing that, our socioty has a special duty to protect young workers. The argument that farmers do not have enough workers is certainly outwaighed by the avalability of clder youth and adult workers in this economy. Challenges that young workers are denied the opportunity to work in agricuture are negated by the facts that young workers can stll be involved in agriculture on the fanily farm, 4-H clubs and once they tum 16. There is no nood for workers under age 16 to be involved in such dangerous work.

I appreciale the Labor Department's attempt to bring protections for children working in agriculture more in Ine with those provided to young workers in non-agricultural jobs. I would also support changes to the Fair Labor Standards Act to provide peobections to 16- and 17-year-old workers, and provide increased protections for thosa under age 14, but I realize that the Labor Departmant does not have authority under the current law to address this vurerable agegroup.

I support the proposed changes to protect children under the age of 16 working in agriculture, including the prchibition to operate ary tracters. I recommend, however, DCL eliminate the exemption that allows children under age 16 to oparate this equipment if they are a "student-leamer." Specifically, the one-ime tractor certifcation training alone is not sufficient for any student-kamor oporating a tractor. Tractors are the leading cause of fatalities in agriculture, and DOL provides no evidence that the training currently provided is effective in eliminating fatalties and inuries among 14-15 yoar olds.

I support the proposed prohibitions and work restrictions described in the cher Hazardous Orders, from the bans on using powered equipment and gravity-operated converors; working at heights above 6 feet; working with, or around potentialy dangerous farm animals, production of tabacco, construction, demolition, excavation, silos and manure pits. I also support the two new Non-agricultural Hazardous Orders involving occupations in farmproduct raw material, such as grain elevators; and the use of electronic dewices while operating power-ditven equipment.

I urge the Labor Department to include in these revisions, protections for young workers from temparahure extremes, such as heat exposure. It should look to the heat stress rogulations in the States of Caifomia and Washington to guide the development of an appropriate Hazardous Order for youth, and include imits on the number of hours they may work under canditions of temperature extremes.

I urge the Wage and Hour Division to complete and adopt changes to these rules by January 2012.

I request that this letter be made part of the public nulamaking recond. 